\title{
Review Article \\ Stem Cells Applications in Regenerative Medicine and Disease Therapeutics
}

\author{
Ranjeet Singh Mahla \\ Department of Biological Sciences, Indian Institute of Science Education and Research (IISER), \\ Bhopal, Madhya Pradesh 462066, India \\ Correspondence should be addressed to Ranjeet Singh Mahla; ranjeet@iiserb.ac.in
}

Received 13 March 2016; Accepted 5 June 2016

Academic Editor: Paul J. Higgins

Copyright (c) 2016 Ranjeet Singh Mahla. This is an open access article distributed under the Creative Commons Attribution License, which permits unrestricted use, distribution, and reproduction in any medium, provided the original work is properly cited.

Regenerative medicine, the most recent and emerging branch of medical science, deals with functional restoration of tissues or organs for the patient suffering from severe injuries or chronic disease. The spectacular progress in the field of stem cell research has laid the foundation for cell based therapies of disease which cannot be cured by conventional medicines. The indefinite self-renewal and potential to differentiate into other types of cells represent stem cells as frontiers of regenerative medicine. The transdifferentiating potential of stem cells varies with source and according to that regenerative applications also change. Advancements in gene editing and tissue engineering technology have endorsed the ex vivo remodelling of stem cells grown into 3D organoids and tissue structures for personalized applications. This review outlines the most recent advancement in transplantation and tissue engineering technologies of ESCs, TSPSCs, MSCs, UCSCs, BMSCs, and iPSCs in regenerative medicine. Additionally, this review also discusses stem cells regenerative application in wildlife conservation.

\section{Introduction}

Regenerative medicine, the most recent and emerging branch of medical science, deals with functional restoration of specific tissue and/or organ of the patients suffering with severe injuries or chronic disease conditions, in the state where bodies own regenerative responses do not suffice [1]. In the present scenario donated tissues and organs cannot meet the transplantation demands of aged and diseased populations that have driven the thrust for search for the alternatives. Stem cells are endorsed with indefinite cell division potential, can transdifferentiate into other types of cells, and have emerged as frontline regenerative medicine source in recent time, for reparation of tissues and organs anomalies occurring due to congenital defects, disease, and age associated effects [1]. Stem cells pave foundation for all tissue and organ system of the body and mediates diverse role in disease progression, development, and tissue repair processes in host. On the basis of transdifferentiation potential, stem cells are of four types, that is, (1) unipotent, (2) multipotent, (3) pluripotent, and (4) totipotent [2]. Zygote, the only totipotent stem cell in human body, can give rise to whole organism through the process of transdifferentiation, while cells from inner cells mass (ICM) of embryo are pluripotent in their nature and can differentiate into cells representing three germ layers but do not differentiate into cells of extraembryonic tissue [2]. Stemness and transdifferentiation potential of the embryonic, extraembryonic, fetal, or adult stem cells depend on functional status of pluripotency factors like OCT4, cMYC, KLF44, NANOG, SOX2, and so forth [3-5]. Ectopic expression or functional restoration of endogenous pluripotency factors epigenetically transforms terminally differentiated cells into ESCs-like cells [3], known as induced pluripotent stem cells (iPSCs) $[3,4]$. On the basis of regenerative applications, stem cells can be categorized as embryonic stem cells (ESCs), tissue specific progenitor stem cells (TSPSCs), mesenchymal stem cells (MSCs), umbilical cord stem cells (UCSCs), bone marrow stem cells (BMSCs), and iPSCs (Figure 1; Table 1). The transplantation of stem cells can be autologous, allogenic, and syngeneic for induction of tissue regeneration and immunolysis of pathogen or malignant cells. For avoiding the consequences of host-versusgraft rejections, tissue typing of human leucocyte antigens (HLA) for tissue and organ transplant as well as use of 
Promises of stem cells in regenerative medicines

(i) Improvement of spinal cord injury

(ii) Regeneration of retinal sheet

(iii) Generation of retinal ganglion cells

(iv) Healing of heart defects

(v) Hepatic cell formation

(vi) Formation of insulin secreting $\beta$-cells

(vii) Cartilage lesion treatment

(viii) Regeneration of pacemaker

(ix) In vitro gametogenesis

(i) Treatment of diabetes and retinopathy

(ii) Neurodental therapeutic applications

(iii) Restoration of cognitive functions

(iv) Brain and cancer treatment

(v) Ear acoustic function restoration

(vi) Regeneration of intestinal mucosa

(vii) Treatment of vision defects

(viii) Muscle regeneration

(ix) Regeneration of fallopian tube

(i) Regeneration of bladder tissue

(ii) Muscle regeneration

(iii) Regeneration of teeth tissue

(iv) Healing of orthopedic injuries

(v) Recovery from muscle injuries

(vi) Hear scar repair after attack
(1)

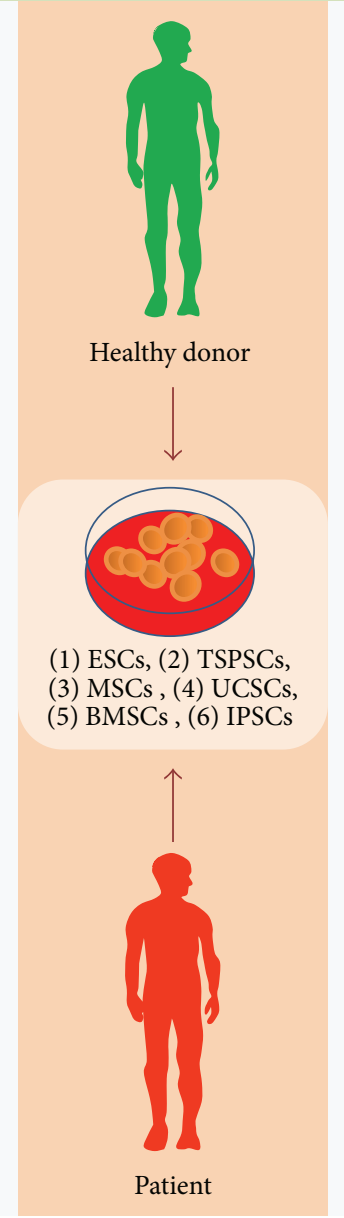

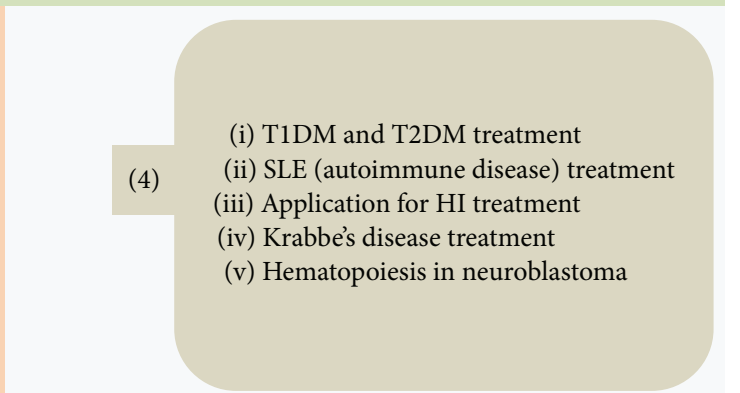

(i) Treatment of anemia and blood cancer

(ii) Retroviral therapy

(5) (iii) Correction of neuronal defects

(iv) Generation of functional platelets

(v) Alveolar bone regeneration

(vi) Regeneration of diaphragm tissue

(i) Regeneration of kidney tissue

(ii) Vision restoration in AMD

(iii) Treatment of placental defects

(6)

(iv) Treatment of brain cortex defects

(v) ASD and autism treatment

(vi) Treatment of liver and lung disease

(vii) Generation of serotonin neurons

(viii) Regeneration of pacemaker

Figure 1: Promises of stem cells in regenerative medicine: the six classes of stem cells, that is, embryonic stem cells (ESCs), tissue specific progenitor stem cells (TSPSCs), mesenchymal stem cells (MSCs), umbilical cord stem cells (UCSCs), bone marrow stem cells (BMSCs), and induced pluripotent stem cells (iPSCs), have many promises in regenerative medicine and disease therapeutics.

immune suppressant is recommended [6]. Stem cells express major histocompatibility complex (MHC) receptor in low and secret chemokine that recruitment of endothelial and immune cells is enabling tissue tolerance at graft site [6]. The current stem cell regenerative medicine approaches are founded onto tissue engineering technologies that combine the principles of cell transplantation, material science, and microengineering for development of organoid; those can be used for physiological restoration of damaged tissue and organs. The tissue engineering technology generates nascent tissue on biodegradable 3D-scaffolds $[7,8]$. The ideal scaffolds support cell adhesion and ingrowths, mimic mechanics of target tissue, support angiogenesis and neovascularisation for appropriate tissue perfusion, and, being nonimmunogenic to host, do not require systemic immune suppressant [9]. Stem cells number in tissue transplant impacts upon regenerative outcome [10]; in that case prior ex vivo expansion of transplantable stem cells is required [11]. For successful regenerative outcomes, transplanted stem cells must survive, proliferate, and differentiate in site specific manner and integrate into host circulatory system [12]. This review provides framework of most recent (Table 1; Figures 1-8) advancement in transplantation and tissue engineering technologies of ESCs, TSPSCs, MSCs, UCSCs, BMSCs, and iPSCs in regenerative medicine. Additionally, this review also discusses stem cells as the tool of regenerative applications in wildlife conservation.

\section{ESCs in Regenerative Medicine}

For the first time in 1998, Thomson isolated human ESCs (hESCs) [13]. ESCs are pluripotent in their nature and can give rise to more than 200 types of cells and promises for the treatment of any kinds of disease [13]. The pluripotency fate of ESCs is governed by functional dynamics of transcription factors OCT4, SOX2, NANOG, and so forth, which are termed as pluripotency factors. The two alleles of the OCT4 are held apart in pluripotency state in ESCs; phase through homologues pairing during embryogenesis 


\begin{tabular}{|c|c|c|c|c|c|c|c|c|c|c|c|c|c|c|}
\hline 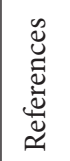 & $\stackrel{n}{\Omega}$ & 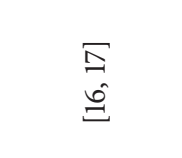 & $\begin{array}{l}\infty \\
\stackrel{\infty}{\sim} \\
\stackrel{2}{2} \\
\stackrel{\infty}{=}\end{array}$ & $\begin{array}{l}\vec{d} \\
\hat{N} \\
\hat{d} \\
\hat{d}\end{array}$ & 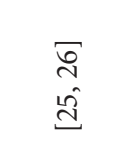 & 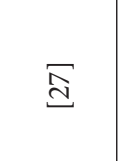 & 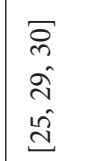 & $\begin{array}{l}\vec{m} \\
\vec{m}\end{array}$ & $\begin{array}{l}\vec{m} \\
m \\
\dot{m}\end{array}$ & 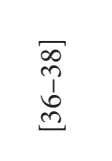 & $\begin{array}{l}\bar{q} \\
\dot{q} \\
\hat{m}\end{array}$ & $\begin{array}{l}\vec{F} \\
\overrightarrow{\mathbb{J}}\end{array}$ & $\begin{array}{l}\text { I } \\
\pm \\
\pm \\
\pm\end{array}$ & $\begin{array}{l}\text { 品 } \\
\stackrel{+}{+}\end{array}$ \\
\hline 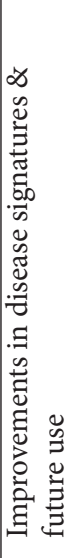 & 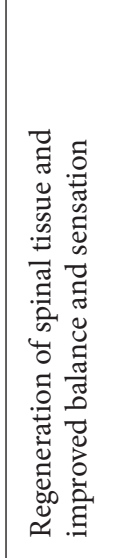 & 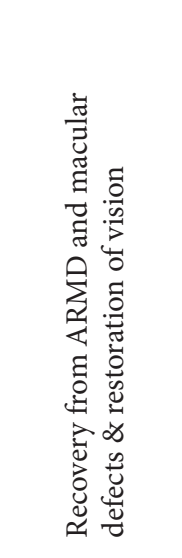 & 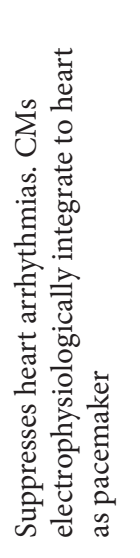 & 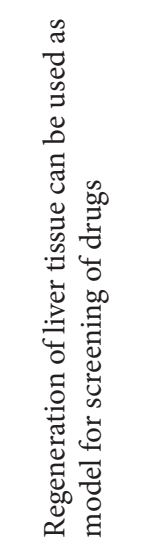 & 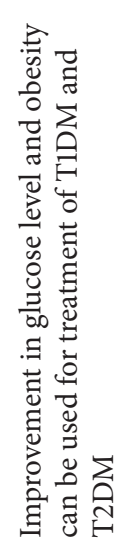 & 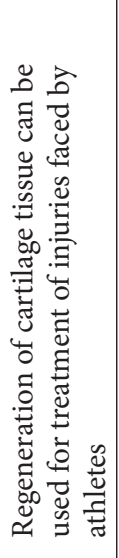 & 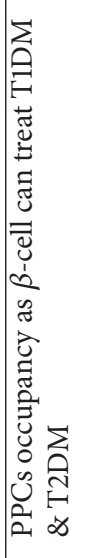 & 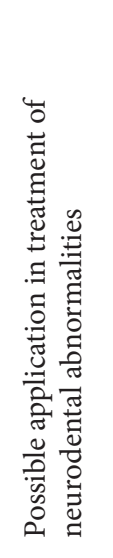 & 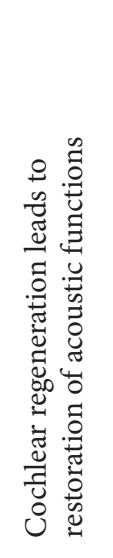 & 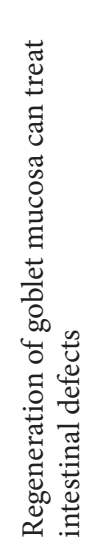 & 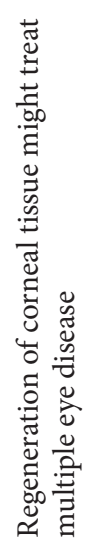 & 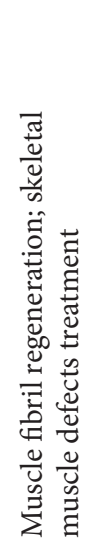 & 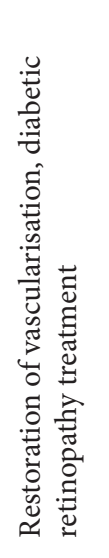 & 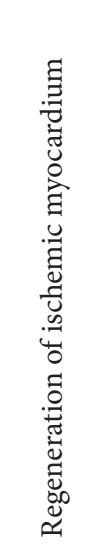 \\
\hline 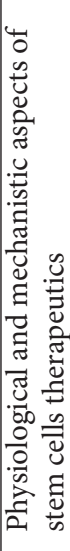 & 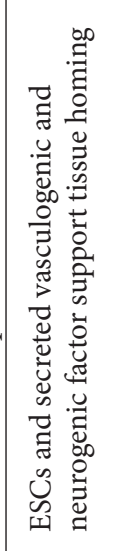 & 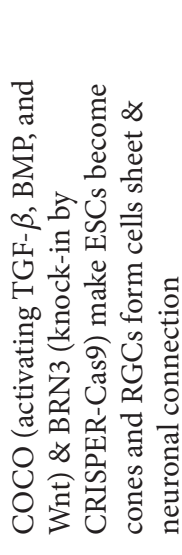 & 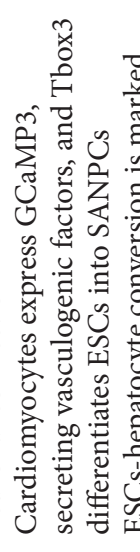 & 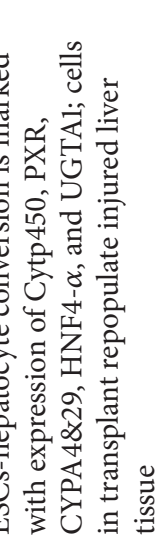 & 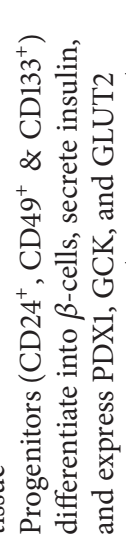 & 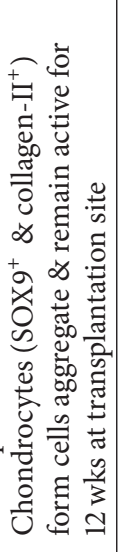 & 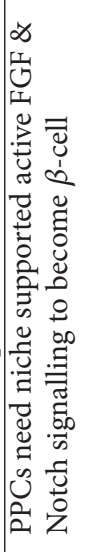 & 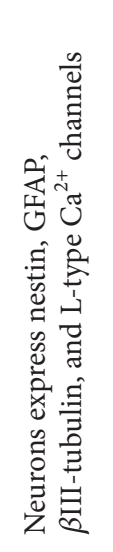 & 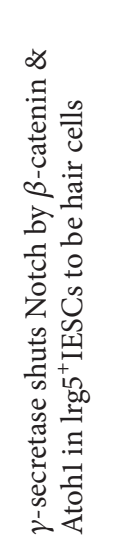 & 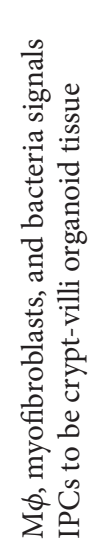 & 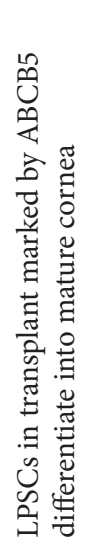 & 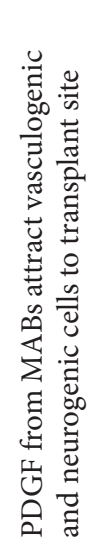 & 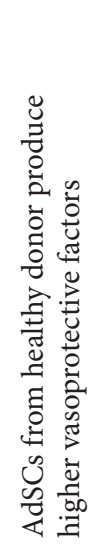 & 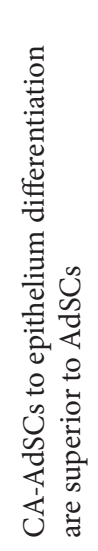 \\
\hline 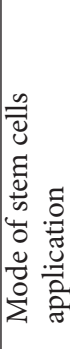 & 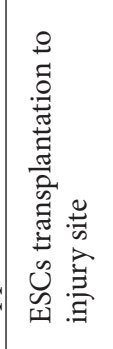 & 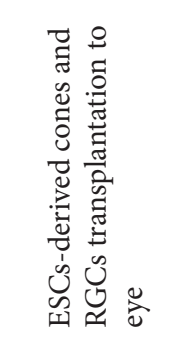 & 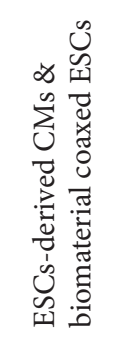 & 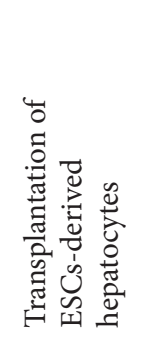 & 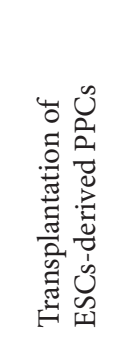 & 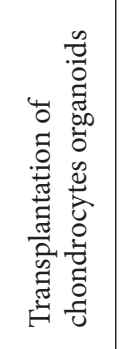 & 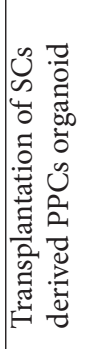 & 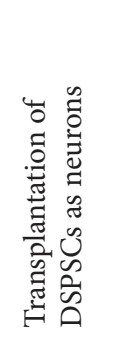 & 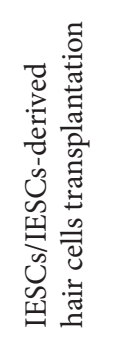 & 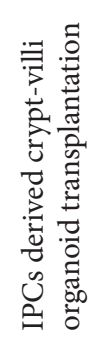 & 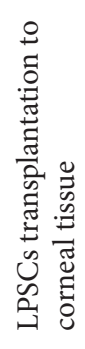 & 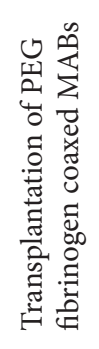 & 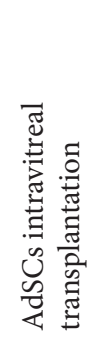 & 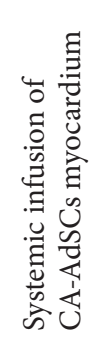 \\
\hline 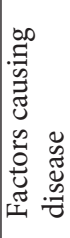 & 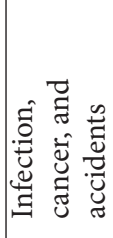 & 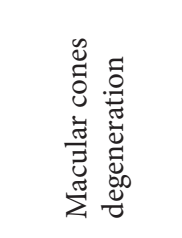 & 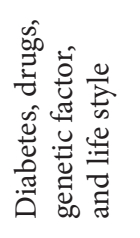 & 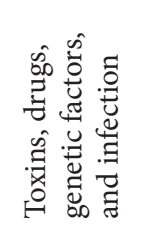 & 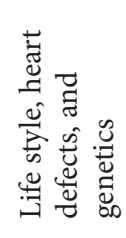 & 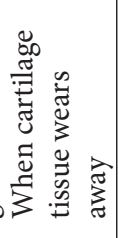 & 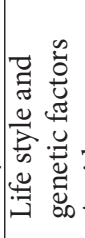 & 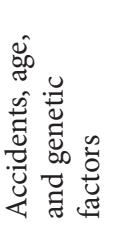 & 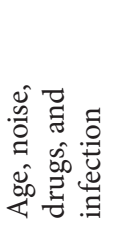 & 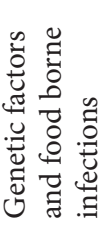 & 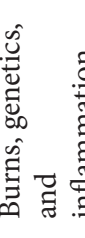 & & 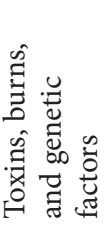 & 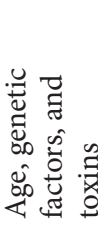 \\
\hline 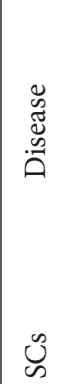 & 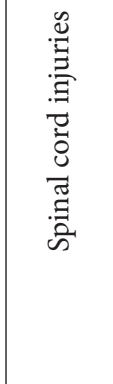 & 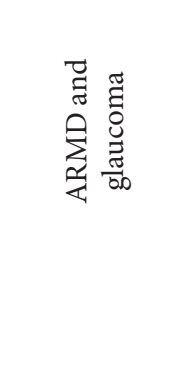 & 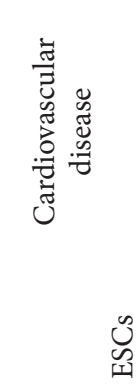 & 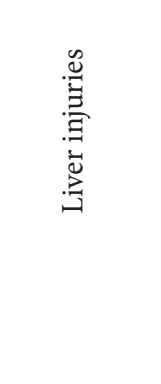 & 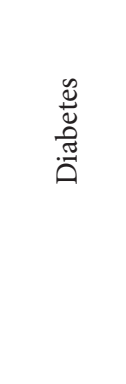 & 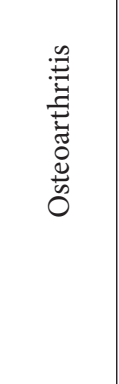 & 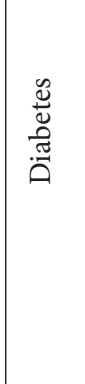 & 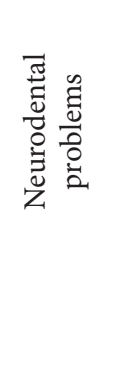 & 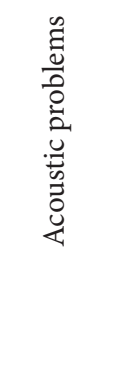 & 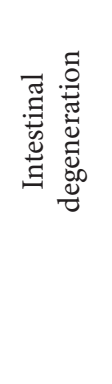 & 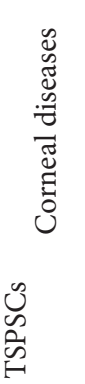 & 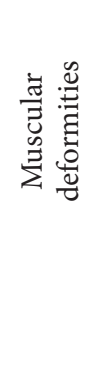 & 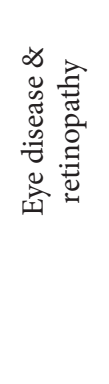 & 密 \\
\hline
\end{tabular}




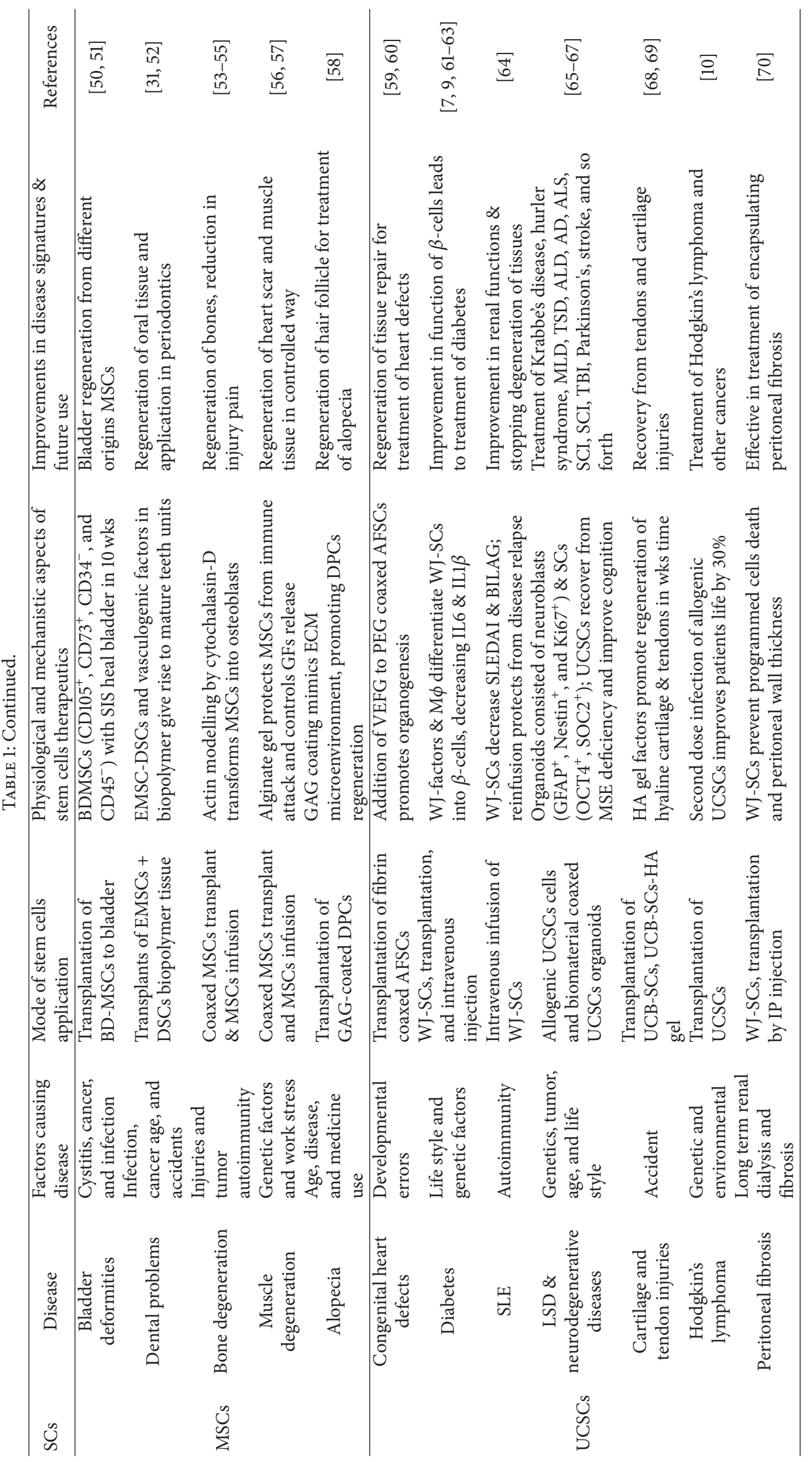




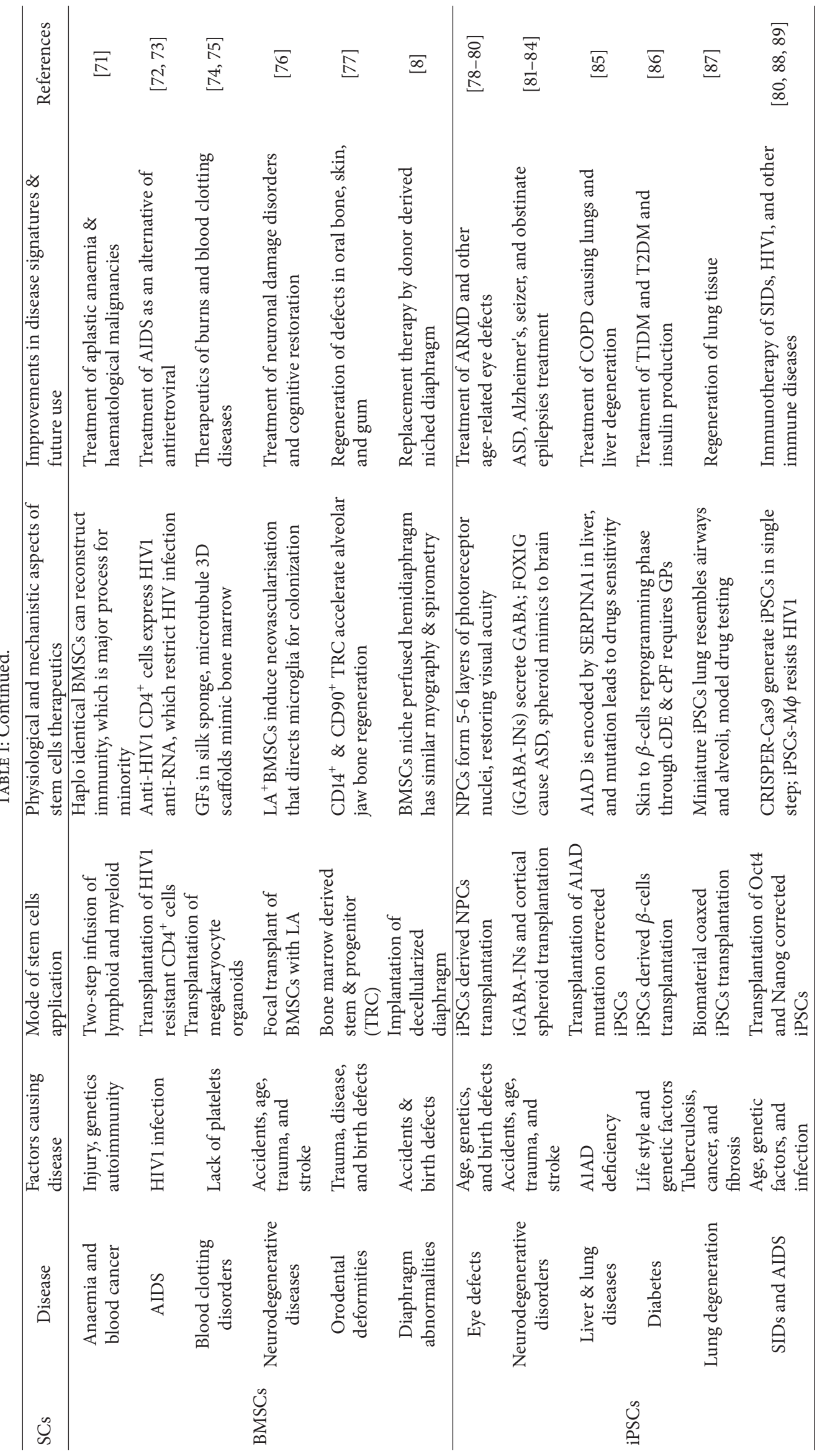




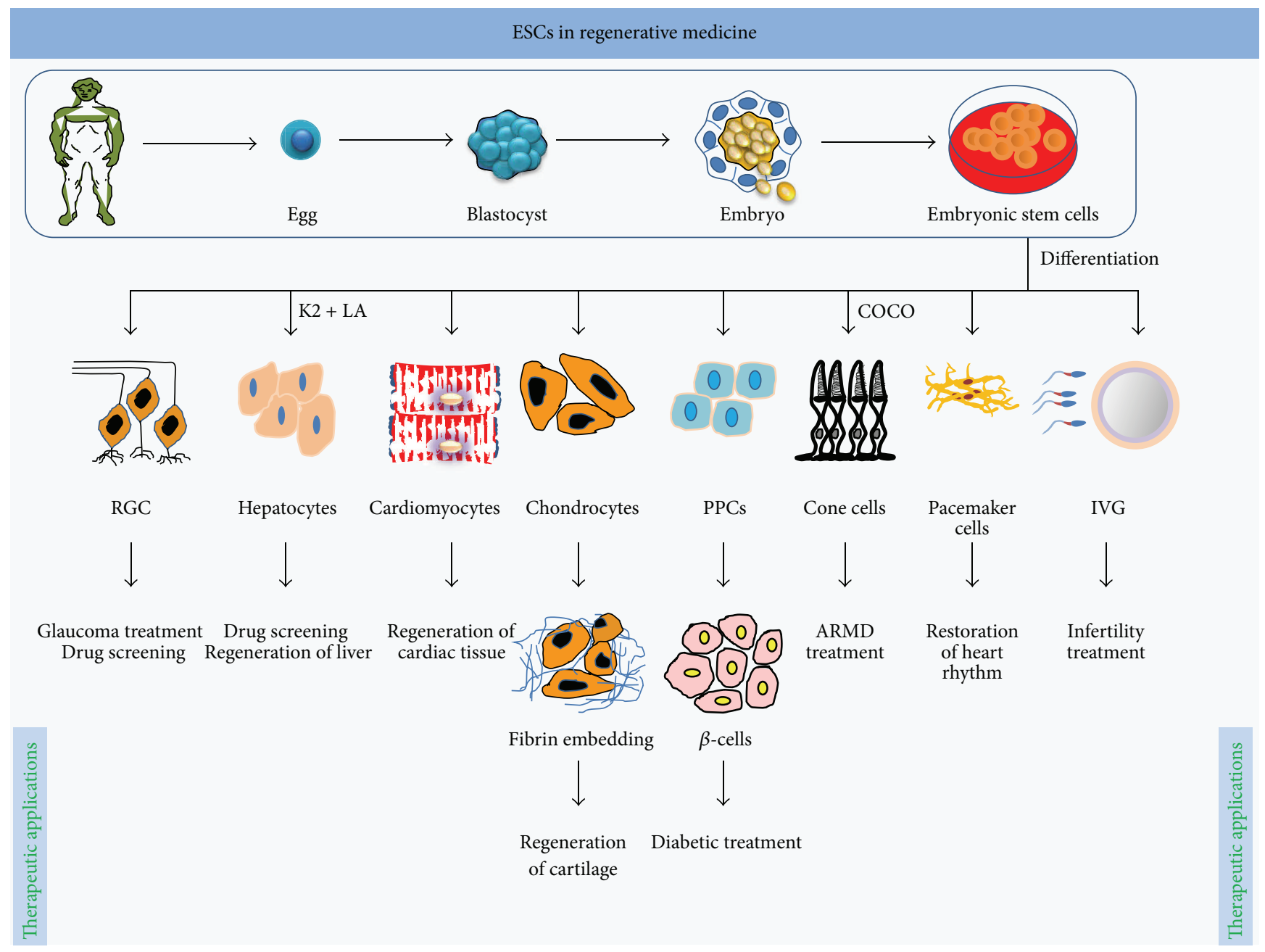

FIGURE 2: ESCs in regenerative medicine: ESCs, sourced from ICM of gastrula, have tremendous promises in regenerative medicine. These cells can differentiate into more than 200 types of cells representing three germ layers. With defined culture conditions, ESCs can be transformed into hepatocytes, retinal ganglion cells, chondrocytes, pancreatic progenitor cells, cone cells, cardiomyocytes, pacemaker cells, eggs, and sperms which can be used in regeneration of tissue and treatment of disease in tissue specific manner.

and transdifferentiation processes [14] has been considered as critical regulatory switch for lineage commitment of ESCs. The diverse lineage commitment potential represents ESCs as ideal model for regenerative therapeutics of disease and tissue anomalies. This section of review on ESCs discusses transplantation and transdifferentiation of ESCs into retinal ganglion, hepatocytes, cardiomyocytes, pancreatic progenitors, chondrocytes, cones, egg sperm, and pacemaker cells (Figure 2; Table 1). Infection, cancer treatment, and accidents can cause spinal cord injuries (SCIs). The transplantation of hESCs to paraplegic or quadriplegic SCI patients improves body control, balance, sensation, and limbal movements [15], where transplanted stem cells do homing to injury sites. By birth, humans have fixed numbers of cone cells; degeneration of retinal pigment epithelium (RPE) of macula in central retina causes age-related macular degeneration (ARMD). The genomic incorporation of COCO gene (expressed during embryogenesis) in the developing embryo leads lineage commitment of ESCs into cone cells, through suppression of
TGF $\beta$, BMP, and Wnt signalling pathways. Transplantation of these cone cells to eye recovers individual from ARMD phenomenon, where transplanted cone cells migrate and form sheet-like structure in host retina [16]. However, establishment of missing neuronal connection of retinal ganglion cells (RGCs), cones, and PRE is the most challenging aspect of ARMD therapeutics. Recently, Donald Z Jacks group at John Hopkins University School of Medicine has generated RGCs from CRISPER-Cas9-m-Cherry reporter ESCs [17]. During ESCs transdifferentiation process, CRIPER-Cas9 directs the knock-in of m-Cherry reporter into $3^{\prime} \mathrm{UTR}$ of BRN3B gene, which is specifically expressed in RGCs and can be used for purification of generated RGCs from other cells [17]. Furthermore, incorporation of forskolin in transdifferentiation regime boosts generation of RGCs. Coaxing of these RGCs into biomaterial scaffolds directs axonal differentiation of RGCs. Further modification in RGCs generation regime and composition of biomaterial scaffolds might enable restoration of vision for ARMD and glaucoma patients [17]. 


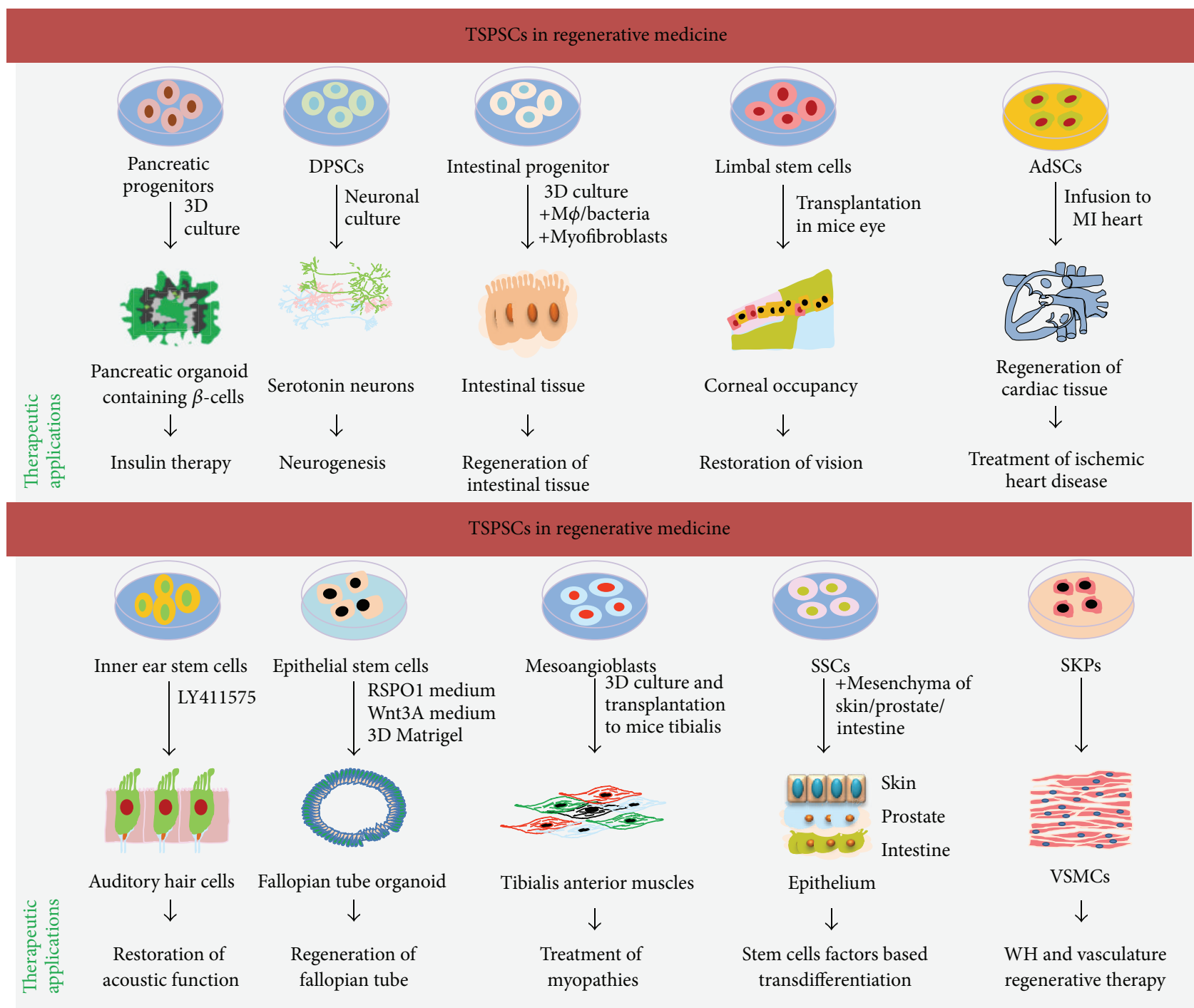

FIGURE 3: TSPSCs in regenerative medicine: tissue specific stem and progenitor cells have potential to differentiate into other cells of the tissue. Characteristically inner ear stem cells can be transformed into auditory hair cells, skin progenitors into vascular smooth muscle cells, mesoangioblasts into tibialis anterior muscles, and dental pulp stem cells into serotonin cells. The 3D-culture of TSPSCs in complex biomaterial gives rise to tissue organoids, such as pancreatic organoid from pancreatic progenitor, intestinal tissue organoids from intestinal progenitor cells, and fallopian tube organoids from fallopian tube epithelial cells. Transplantation of TSPSCs regenerates targets tissue such as regeneration of tibialis muscles from mesoangioblasts, cardiac tissue from AdSCs, and corneal tissue from limbal stem cells. Cell growth and transformation factors secreted by TSPSCs can change cells fate to become other types of cell, such that SSCs coculture with skin, prostate, and intestine mesenchyme transforms these cells from MSCs into epithelial cells fate.

Globally, especially in India, cardiovascular problems are a more common cause of human death, where biomedical therapeutics require immediate restoration of heart functions for the very survival of the patient. Regeneration of cardiac tissue can be achieved by transplantation of cardiomyocytes, ESCs-derived cardiovascular progenitors, and bone marrow derived mononuclear cells (BMDMNCs); however healing by cardiomyocytes and progenitor cells is superior to BMDMNCs but mature cardiomyocytes have higher tissue healing potential, suppress heart arrhythmias, couple electromagnetically into hearts functions, and provide mechanical and electrical repair without any associated tumorigenic effects
$[18,19]$. Like CM differentiation, ESCs derived liver stem cells can be transformed into Cytp450-hepatocytes, mediating chemical modification and catabolism of toxic xenobiotic drugs [20]. Even today, availability and variability of functional hepatocytes are a major a challenge for testing drug toxicity [20]. Stimulation of ESCs and ex vivo VitK12 and lithocholic acid (a by-product of intestinal flora regulating drug metabolism during infancy) activates pregnane $\mathrm{X}$ receptor (PXR), CYP3A4, and CYP2C9, which leads to differentiation of ESCs into hepatocytes; those are functionally similar to primary hepatocytes, for their ability to produce albumin and apolipoprotein B100 [20]. These hepatocytes 


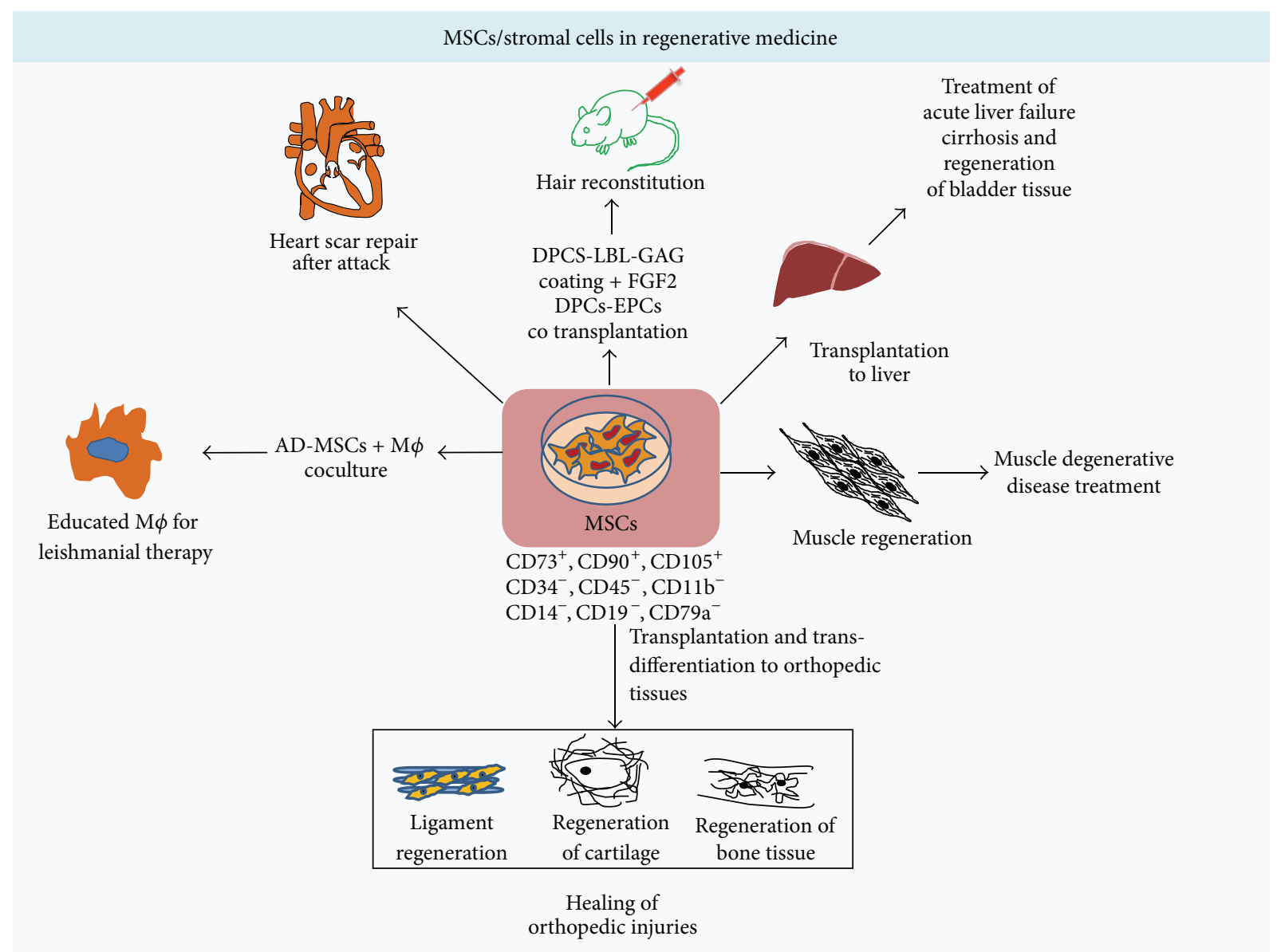

FIGURE 4: MSCs in regenerative medicine: mesenchymal stem cells are CD73 ${ }^{+}, \mathrm{CD}^{+} 0^{+}, \mathrm{CD} 105^{+}, \mathrm{CD} 34^{-}, \mathrm{CD}^{-} 5^{-}, \mathrm{CD} 11 \mathrm{~b}^{-}, \mathrm{CD}^{-} 4^{-}, \mathrm{CD} 19^{-}$, and $\mathrm{CD}_{79} \mathrm{a}^{-}$cells, also known as stromal cells. These bodily MSCs represented here do not account for MSCs of bone marrow and umbilical cord. Upon transplantation and transdifferentiation these bodily MSCs regenerate into cartilage, bones, and muscles tissue. Heart scar formed after heart attack and liver cirrhosis can be treated from MSCs. ECM coating provides the niche environment for MSCs to regenerate into hair follicle, stimulating hair growth.

are excellent source for the endpoint screening of drugs for accurate prediction of clinical outcomes [20]. Generation of hepatic cells from ESCs can be achieved in multiple ways, as serum-free differentiation [21], chemical approaches [20, $22]$, and genetic transformation [23, 24]. These ESCs-derived hepatocytes are long lasting source for treatment of liver injuries and high throughput screening of drugs [20,23, 24]. Transplantation of the inert biomaterial encapsulated hESCsderived pancreatic progenitors $\left(\mathrm{CD} 24^{+}, \mathrm{CD} 49^{+}\right.$, and $\mathrm{CD} 133^{+}$) differentiates into $\beta$-cells, minimizing high fat diet induced glycemic and obesity effects in mice [25] (Table 1). Addition of antidiabetic drugs into transdifferentiation regime can boost ESCs conservation into $\beta$-cells [25], which theoretically can cure T2DM permanently [25]. ESCs can be differentiated directly into insulin secreting $\beta$-cells (marked with GLUT2, INS1, GCK, and PDX1) which can be achieved through PDX1 mediated epigenetic reprogramming [26]. Globally, osteoarthritis affects millions of people and occurs when cartilage at joints wears away, causing stiffness of the joints. The available therapeutics for arthritis relieve symptoms but do not initiate reverse generation of cartilage. For young individuals and athletes replacement of joints is not feasible like old populations; in that case transplantation of stem cells represents an alternative for healing cartilage injuries [27]. Chondrocytes, the cartilage forming cells derived from $\mathrm{hESC}$, embedded in fibrin gel effectively heal defective cartilage within 12 weeks, when transplanted to focal cartilage defects of knee joints in mice without any negative effect [27]. Transplanted chondrocytes form cell aggregates, positive for SOX9 and collagen II, and defined chondrocytes are active for more than 12 wks at transplantation site, advocating clinical suitability of chondrocytes for treatment of cartilage lesions [27]. The integrity of ESCs to integrate and differentiate into electrophysiologically active cells provides a means for natural regulation of heart rhythm as biological pacemaker. Coaxing of ESCs into inert biomaterial as well as propagation in defined culture conditions leads to transdifferentiation of ESCs to become sinoatrial node (SAN) pacemaker cells (PCs) [28]. Genomic incorporation TBox3 into ESCs ex vivo leads to generation of PCs-like cells; those express activated leukocyte cells adhesion molecules (ALCAM) and exhibit similarity to PCs for gene expression and immune 


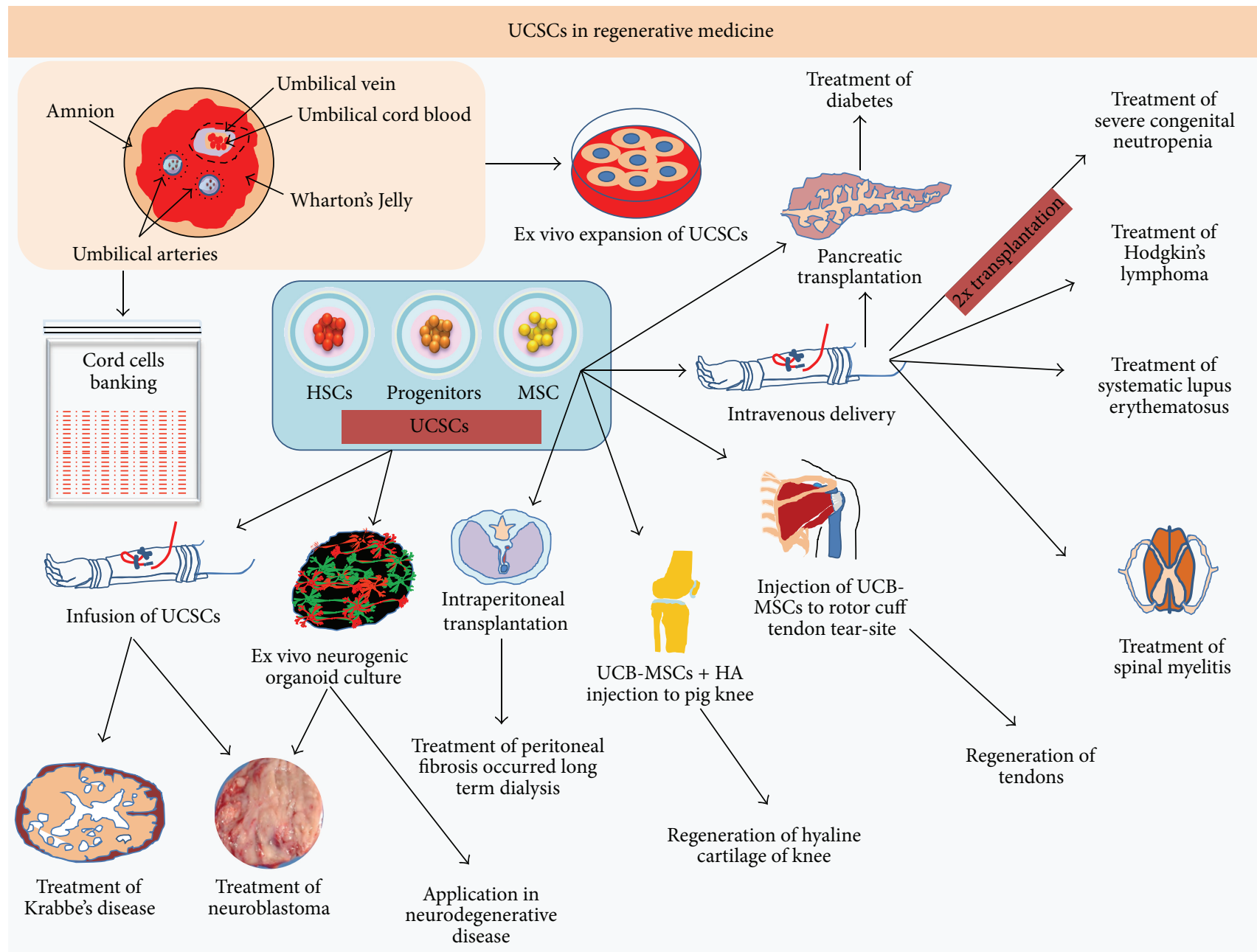

FIGURE 5: UCSCs in regenerative medicine: umbilical cord, the readily available source of stem cells, has emerged as futuristic source for personalized stem cell therapy. Transplantation of UCSCs to Krabbe's disease patients regenerates myelin tissue and recovers neuroblastoma patients through restoring tissue homeostasis. The UCSCs organoids are readily available tissue source for treatment of neurodegenerative disease. Peritoneal fibrosis caused by long term dialysis, tendon tissue degeneration, and defective hyaline cartilage can be regenerated by UCSCs. Intravenous injection of UCSCs enables treatment of diabetes, spinal myelitis, systemic lupus erythematosus, Hodgkin's lymphoma, and congenital neuropathies. Cord blood stem cells banking avails long lasting source of stem cells for personalized therapy and regenerative medicine.

functions [28]. Transplantation of PCs can restore pacemaker functions of the ailing heart [28]. In summary, ESCs can be transdifferentiated into any kinds of cells representing three germ layers of the body, being most promising source of regenerative medicine for tissue regeneration and disease therapy (Table 1). Ethical concerns limit the applications of ESCs, where set guidelines need to be followed; in that case TSPSCs, MSCs, UCSCs, BMSCs, and iPSCs can be explored as alternatives.

\section{TSPSCs in Regenerative Medicine}

TSPSCs maintain tissue homeostasis through continuous cell division, but, unlike ESCs, TSPSCs retain stem cells plasticity and differentiation in tissue specific manner, giving rise to few types of cells (Table 1). The number of TSPSCs population to total cells population is too low; in that case their harvesting as well as in vitro manipulation is really a tricky task [29], to explore them for therapeutic scale. Human body has foundation from various types of TSPSCs; discussing the therapeutic application for all types is not feasible. This section of review discusses therapeutic application of pancreatic progenitor cells (PPCs), dental pulp stem cells (DPSCs), inner ear stem cells (IESCs), intestinal progenitor cells (IPCs), limbal progenitor stem cells (LPSCs), epithelial progenitor stem cells (EPSCs), mesoangioblasts (MABs), spermatogonial stem cells (SSCs), the skin derived precursors (SKPs), and adipose derived stem cells (AdSCs) (Figure 3; Table 1). During embryogenesis PPCs give rise to insulin-producing $\beta$-cells. The differentiation of PPCs to become $\beta$-cells is negatively regulated by insulin [30]. PPCs require active FGF and Notch signalling; growing more rapidly in community than in single cell populations 


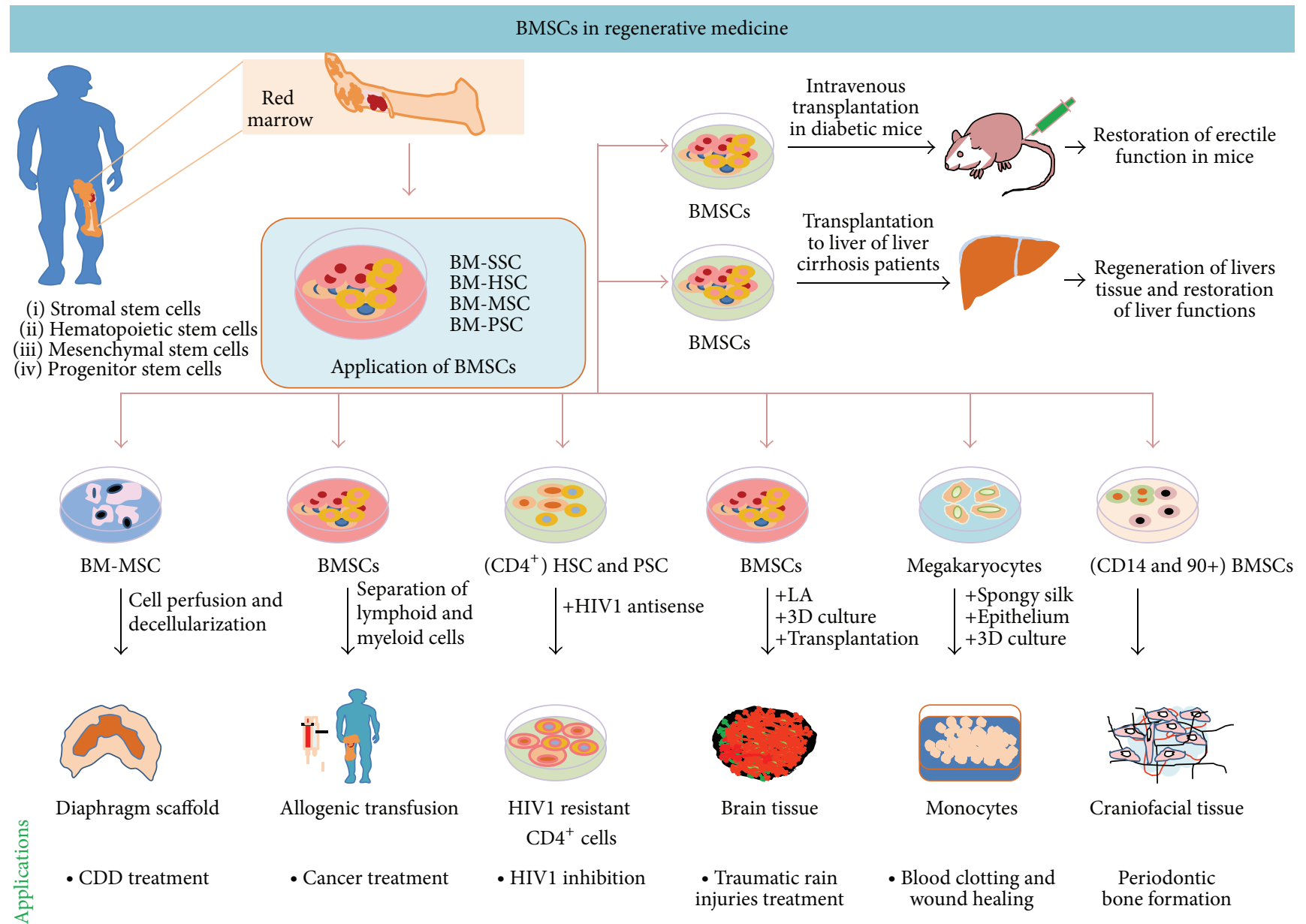

FIGURE 6: BMSCs in regenerative medicine: bone marrow, the soft sponge bone tissue that consisted of stromal, hematopoietic, and mesenchymal and progenitor stem cells, is responsible for blood formation. Even halo-HLA matched BMSCs can cure from disease and regenerate tissue. BMSCs can regenerate craniofacial tissue, brain tissue, diaphragm tissue, and liver tissue and restore erectile function and transdifferentiation monocytes. These multipotent stem cells can cure host from cancer and infection of HIV and HCV.

advocates the functional importance of niche effect in selfrenewal and transdifferentiation processes. In 3D-scaffold culture system, mice embryo derived PPCs grow into hollow organoid spheres; those finally differentiate into insulinproducing $\beta$-cell clusters [29]. The DSPSCs, responsible for maintenance of teeth health status, can be sourced from apical papilla, deciduous teeth, dental follicle, and periodontal ligaments, have emerged as regenerative medicine candidate, and might be explored for treatment of various kinds of disease including restoration neurogenic functions in teeth $[31,32]$. Expansion of DSPSCs in chemically defined neuronal culture medium transforms them into a mixed population of cholinergic, GABAergic, and glutaminergic neurons; those are known to respond towards acetylcholine, GABA, and glutamine stimulations in vivo. These transformed neuronal cells express nestin, glial fibrillary acidic protein (GFAP), $\beta$ III-tubulin, and voltage gated L-type $\mathrm{Ca}^{2+}$ channels [32]. However, absence of $\mathrm{Na}^{+}$and $\mathrm{K}^{+}$channels does not support spontaneous action potential generation, necessary for response generation against environmental stimulus. All together, these primordial neuronal stem cells have possible therapeutic potential for treatment of neurodental problems [32]. Sometimes, brain tumor chemotherapy can cause neurodegeneration mediated cognitive impairment, a condition known as chemobrain [33]. The intrahippocampal transplantation of human derived neuronal stem cells to cyclophosphamide behavioural decremented mice restores cognitive functions in a month time. Here the transplanted stem cells differentiate into neuronal and astroglial lineage, reduce neuroinflammation, and restore microglial functions [33]. Furthermore, transplantation of stem cells, followed by chemotherapy, directs pyramidal and granule-cell neurons of the gyrus and CA1 subfields of hippocampus which leads to reduction in spine and dendritic cell density in the brain. These findings suggest that transplantation of stem cells to cranium restores cognitive functions of the chemobrain [33]. The hair cells of the auditory system produced during development are not postmitotic; loss of hair cells cannot be replaced by inner ear stem cells, due to active state of the Notch signalling [34]. Stimulation of inner ear 
iPSCs in regenerative medicine

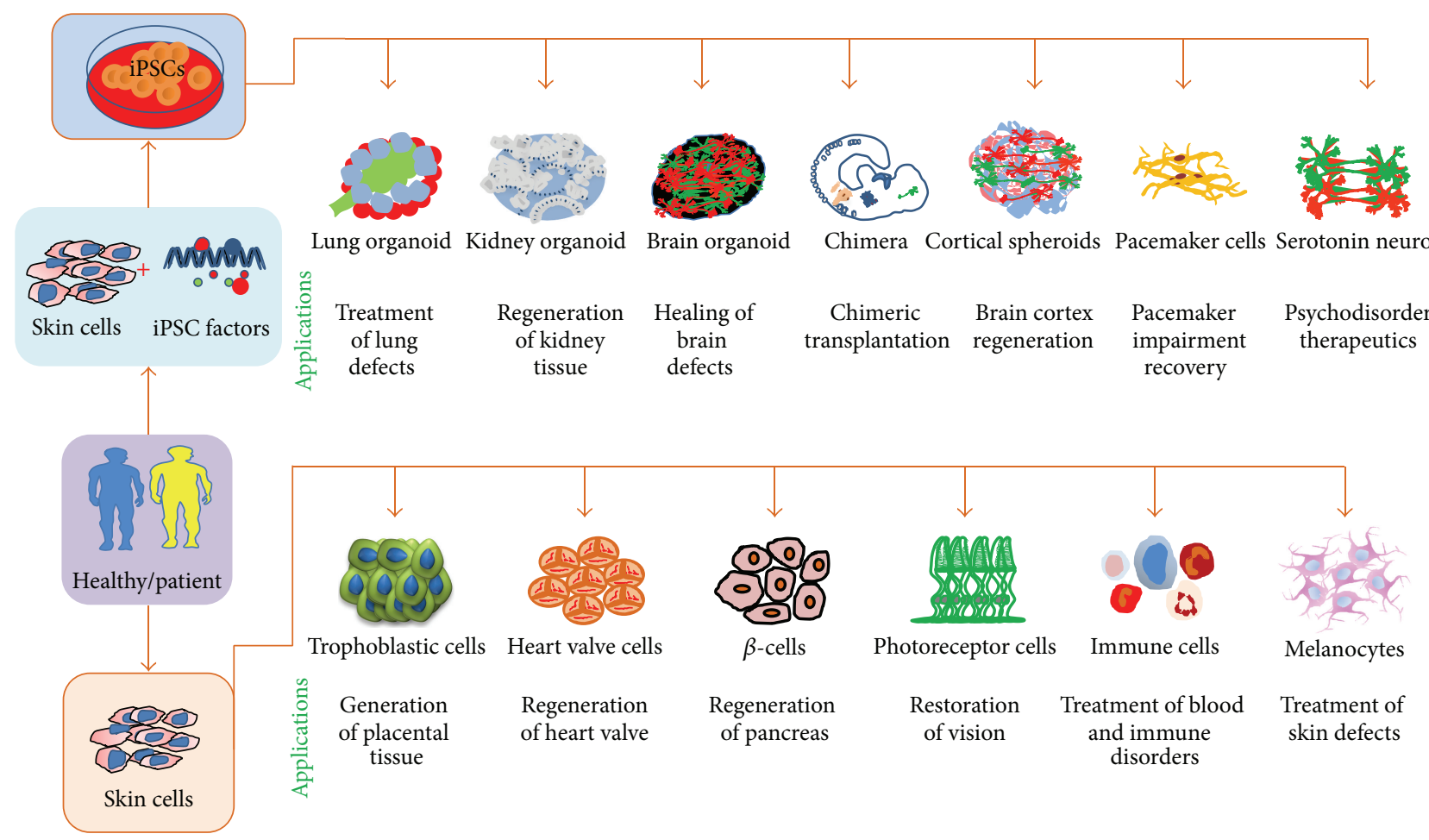

FIGURE 7: iPSCs in regenerative medicine: using the edge of iPSCs technology, skin fibroblasts and other adult tissues derived, terminally differentiated cells can be transformed into ESCs-like cells. It is possible that adult cells can be transformed into cells of distinct lineages bypassing the phase of pluripotency. The tissue specific defined culture can transform skin cells to become trophoblast, heart valve cells, photoreceptor cells, immune cells, melanocytes, and so forth. ECM complexation with iPSCs enables generation of tissue organoids for lung, kidney, brain, and other organs of the body. Similar to ESCs, iPSCs also can be transformed into cells representing three germ layers such as pacemaker cells and serotonin cells.

progenitors with $\Upsilon$-secretase inhibitor (LY411575) abrogates Notch signalling through activation of transcription factor atonal homologue 1 (Atoh1) and directs transdifferentiation of progenitors into cochlear hair cells [34]. Transplantation of in vitro generated hair cells restores acoustic functions in mice, which can be the potential regenerative medicine candidates for the treatment of deafness [34]. Generation of the hair cells also can be achieved through overexpression of $\beta$-catenin and Atoh1 in $\operatorname{Lrg} 5^{+}$cells in vivo [35]. Similar to ear progenitors, intestine of the digestive tract also has its own tissue specific progenitor stem cells, mediating regeneration of the intestinal tissue $[34,36]$. Dysregulation of the common stem cells signalling pathways, Notch/BMP/TGF- $\beta /$ Wnt, in the intestinal tissue leads to disease. Information on these signalling pathways [37] is critically important in designing therapeutics. Coaxing of the intestinal tissue specific progenitors with immune cells (macrophages), connective tissue cells (myofibroblasts), and probiotic bacteria into 3D-scaffolds of inert biomaterial, crafting biological environment, is suitable for differentiation of progenitors to occupy the crypt-villi structures into these scaffolds [36]. Omental implementation of these crypt-villi structures to dogs enhances intestinal mucosa through regeneration of goblet cells containing intestinal tissue [36]. These intestinal scaffolds are close approach for generation of implantable intestinal tissue, divested by infection, trauma, cancer, necrotizing enterocolitis (NEC), and so forth [36]. In vitro culture conditions cause differentiation of intestinal stem cells to become other types of cells, whereas incorporation of valproic acid and CHIR-99021 in culture conditions avoids differentiation of intestinal stem cells, enabling generation of indefinite pool of stem cells to be used for regenerative applications [38]. The limbal stem cells of the basal limbal epithelium, marked with $\mathrm{ABCB} 5$, are essential for regeneration and maintenance of corneal tissue [39]. Functional status of ABCB5 is critical for survival and functional integrity of limbal stem cells, protecting them from apoptotic cell death [39]. Limbal stem cells deficiency leads to replacement of corneal epithelium with visually dead conjunctival tissue, which can be contributed by burns, inflammation, and genetic factors [40]. Transplanted human cornea stem cells to mice regrown into fully functional human cornea, possibly supported by blood eye barrier phenomena, can be used for treatment of eye diseases, where regeneration of corneal tissue is critically required for vision restoration [39]. Muscle degenerative disease like duchenne muscular dystrophy (DMD) can cause 


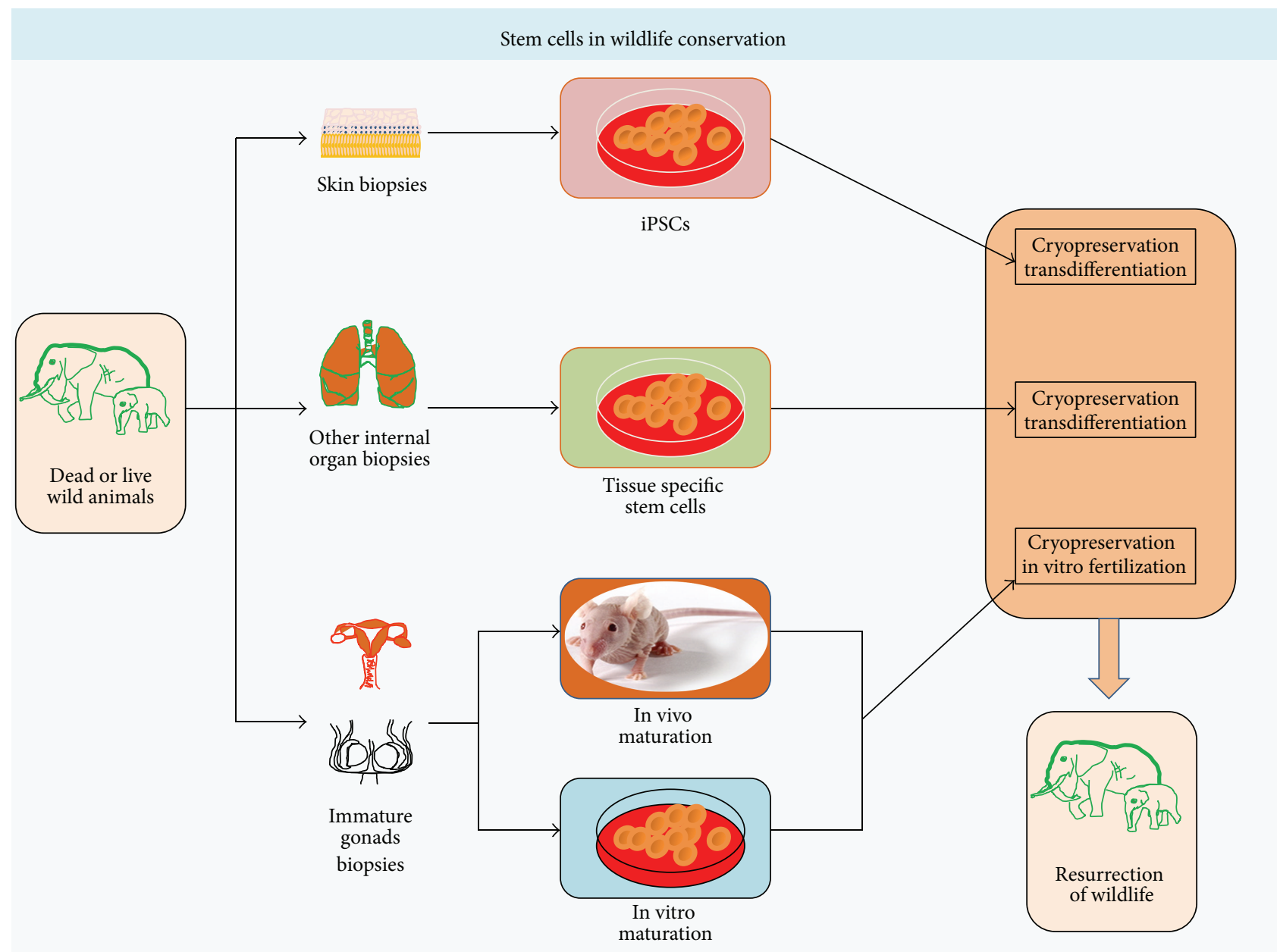

FIGURE 8: Stem cells in wildlife conservation: tissue biopsies obtained from dead and live wild animals can be either cryopreserved or transdifferentiated to other types of cells, through culture in defined culture medium or in vivo maturation. Stem cells and adult tissue derived iPSCs have great potential of regenerative medicine and disease therapeutics. Gonadal tissue procured from dead wild animals can be matured, ex vivo and in vivo for generation of sperm and egg, which can be used for assistive reproductive technology oriented captive breeding of wild animals or even for resurrection of wildlife.

extensive thrashing of muscle tissue, where tissue engineering technology can be deployed for functional restoration of tissue through regeneration [41]. Encapsulation of mouse or human derived MABs (engineered to express placental derived growth factor (PDGF)) into polyethylene glycol (PEG) fibrinogen hydrogel and their transplantation beneath the skin at ablated tibialis anterior form artificial muscles, which are functionally similar to those of normal tibialis anterior muscles [41]. The PDGF attracts various cell types of vasculogenic and neurogenic potential to the site of transplantation, supporting transdifferentiation of mesoangioblasts to become muscle fibrils [41]. The therapeutic application of MABs in skeletal muscle regeneration and other therapeutic outcomes has been reviewed by others [42]. One of the most important tissue specific stem cells, the male germline stem cells or spermatogonial stem cells (SSCs), produces spermatogenic lineage through mesenchymal and epithets cells [43] which itself creates niche effect on other cells. In vivo transplantation of SSCs with prostate, skin, and uterine mesenchyme leads to differentiation of these cells to become epithelia of the tissue of origin [43]. These newly formed tissues exhibit all physical and physiological characteristics of prostate and skin and the physical characteristics of prostate, skin, and uterus, express tissue specific markers, and suggest that factors secreted from SSCs lead to lineage conservation which defines the importance of niche effect in regenerative medicine [43]. According to an estimate, more than 100 million people are suffering from the condition of diabetic retinopathy, a progressive dropout of vascularisation in retina that leads to loss of vision [44]. The intravitreal injection of adipose derived stem cells (AdSCs) to the eye restores microvascular capillary bed in mice. The AdSCs from healthy donor produce higher amounts of vasoprotective factors compared to glycemic mice, enabling superior vascularisation [44]. However use of AdSCs for disease therapeutics needs further standardization for cell counts in dose of transplant and monitoring of therapeutic outcomes at population scale [44]. Apart from AdSCs, other kinds of stem cells also have therapeutic potential in regenerative medicine for treatment of eye defects, which has been 
reviewed by others [45]. Fallopian tubes, connecting ovaries to uterus, are the sites where fertilization of the egg takes place. Infection in fallopian tubes can lead to inflammation, tissue scarring, and closure of the fallopian tube which often leads to infertility and ectopic pregnancies. Fallopian is also the site where onset of ovarian cancer takes place. The studies on origin and etiology of ovarian cancer are restricted due to lack of technical advancement for culture of epithelial cells. The in vitro 3D organoid culture of clinically obtained fallopian tube epithelial cells retains their tissue specificity, keeps cells alive, which differentiate into typical ciliated and secretory cells of fallopian tube, and advocates that ectopic examination of fallopian tube in organoid culture settings might be the ideal approach for screening of cancer [46]. The sustained growth and differentiation of fallopian TSPSCs into fallopian tube organoid depend both on the active state of the Wnt and on paracrine Notch signalling [46]. Similar to fallopian tube stem cells, subcutaneous visceral tissue specific cardiac adipose (CA) derived stem cells (AdSCs) have the potential of differentiation into cardiovascular tissue [47]. Systemic infusion of CA-AdSCs into ischemic myocardium of mice regenerates heart tissue and improves cardiac function through differentiation to endothelial cells, vascular smooth cells, and cardiomyocytes and vascular smooth cells. The differentiation and heart regeneration potential of CAAdSCs are higher than AdSCs [48], representing CA-AdSCs as potent regenerative medicine candidates for myocardial ischemic therapy [47]. The skin derived precursors (SKPs), the progenitors of dermal papilla/hair/hair sheath, give rise to multiple tissues of mesodermal and/or ectodermal origin such as neurons, Schwann cells, adipocytes, chondrocytes, and vascular smooth muscle cells (VSMCs). VSMCs mediate wound healing and angiogenesis process can be derived from human foreskin progenitor SKPs, suggesting that SKPs derived VSMCs are potential regenerative medicine candidates for wound healing and vasculature injuries treatments [49]. In summary, TSPSCs are potentiated with tissue regeneration, where advancement in organoid culture (Figure 3; Table 1) technologies defines the importance of niche effect in tissue regeneration and therapeutic outcomes of ex vivo expanded stem cells.

\section{MSCs/Stromal Cells in Regenerative Medicine}

MSCs, the multilineage stem cells, differentiate only to tissue of mesodermal origin, which includes tendons, bone, cartilage, ligaments, muscles, and neurons [50]. MSCs are the cells which express combination of markers: $\mathrm{CD}^{+} 3^{+}$, $\mathrm{CD}^{+}{ }^{+}, \mathrm{CD}_{105}{ }^{+}, \mathrm{CD}_{11}{ }^{-}, \mathrm{CD} 14^{-}, \mathrm{CD} 19^{-}, \mathrm{CD} 34^{-}, \mathrm{CD} 45^{-}$, $\mathrm{CD} \mathrm{a}^{-}$, and HLA-DR, reviewed elsewhere [50]. The application of MSCs in regenerative medicine can be generalized from ongoing clinical trials, phasing through different state of completions, reviewed elsewhere [90]. This section of review outlines the most recent representative applications of MSCs (Figure 4; Table 1). The anatomical and physiological characteristics of both donor and receiver have equal impact on therapeutic outcomes. The bone marrow derived MSCs
(BMDMSCs) from baboon are morphologically and phenotypically similar to those of bladder stem cells and can be used in regeneration of bladder tissue. The BMDMSCs $\left(\mathrm{CD}_{105}{ }^{+}\right.$, $\mathrm{CD}_{3}{ }^{+}, \mathrm{CD}^{-} 4^{-}$, and $\mathrm{CD} 45^{-}$), expressing GFP reporter, coaxed with small intestinal submucosa (SIS) scaffolds, augment healing of degenerated bladder tissue within $10 \mathrm{wks}$ of the transplantation [51]. The combinatorial CD characterized MACs are functionally active at transplantation site, which suggests that CD characterization of donor MSCs yields superior regenerative outcomes [51]. MSCs also have potential to regenerate liver tissue and treat liver cirrhosis, reviewed elsewhere [91]. The regenerative medicinal application of MSCs utilizes cells in two formats as direct transplantation or first transdifferentiation and then transplantation; ex vivo transdifferentiation of MSCs deploys retroviral delivery system that can cause oncogenic effect on cells. Nonviral, NanoScript technology, comprising utility of transcription factors (TFs) functionalized gold nanoparticles, can target specific regulatory site in the genome effectively and direct differentiation of MSCs into another cell fate, depending on regime of TFs. For example, myogenic regulatory factor containing NanoScript-MRF differentiates the adipose tissue derived MSCs into muscle cells [92]. The multipotency characteristics represent MSCs as promising candidate for obtaining stable tissue constructs through coaxed $3 \mathrm{D}$ organoid culture; however heterogeneous distribution of MSCs slows down cell proliferation, rendering therapeutic applications of MSCs. Adopting two-step culture system for MSCs can yield homogeneous distribution of MSCs in biomaterial scaffolds. For example, fetal-MSCs coaxed in biomaterial when cultured first in rotating bioreactor followed with static culture lead to homogeneous distribution of MSCs in ECM components [7]. Occurrence of dental carries, periodontal disease, and tooth injury can impact individual's health, where bioengineering of teeth can be the alternative option. Coaxing of epithelial-MSCs with dental stem cells into synthetic polymer gives rise to mature teeth unit, which consisted of mature teeth and oral tissue, offering multiple regenerative therapeutics, reviewed elsewhere [52]. Like the tooth decay, both human and animals are prone to orthopedic injuries, affecting bones, joint, tendon, muscles, cartilage, and so forth. Although natural healing potential of bone is sufficient to heal the common injuries, severe trauma and tumor-recession can abrogate germinal potential of bone-forming stem cells. In vitro chondrogenic, osteogenic, and adipogenic potential of MSCs advocates therapeutic applications of MSCs in orthopedic injuries [53]. Seeding of MSCs, coaxed into biomaterial scaffolds, at defective bone tissue, regenerates defective bone tissues, within four wks of transplantation; by the end of 32 wks newly formed tissues integrate into old bone [54]. Osteoblasts, the bone-forming cells, have lesser actin cytoskeleton compared to adipocytes and MSCs. Treatment of MSCs with cytochalasin-D causes rapid transportation of G-actin, leading to osteogenic transformation of MSCs. Furthermore, injection of cytochalasin-D to mice tibia also promotes bone formation within a wk time frame [55]. The bone formation processes in mice, dog, and human are fundamentally similar, so outcomes of research on mice and dogs can be directional for regenerative application to 
human. Injection of MSCs to femur head of Legg-CalvePerthes suffering dog heals the bone very fast and reduces the injury associated pain [55]. Degeneration of skeletal muscle and muscle cramps are very common to sledge dogs, animals, and individuals involved in adventurous athletics activities. Direct injection of adipose tissue derived MSCs to tear-site of semitendinosus muscle in dogs heals injuries much faster than traditional therapies [56]. Damage effect treatment for heart muscle regeneration is much more complex than regeneration of skeletal muscles, which needs high grade fine-tuned coordination of neurons with muscles. Coaxing of MSCs into alginate gel increases cell retention time that leads to releasing of tissue repairing factors in controlled manner. Transplantation of alginate encapsulated cells to mice heart reduces scar size and increases vascularisation, which leads to restoration of heart functions. Furthermore, transplanted MSCs face host inhospitable inflammatory immune responses and other mechanical forces at transplantation site, where encapsulation of cells keeps them away from all sorts of mechanical forces and enables sensing of host tissue microenvironment, and respond accordingly [57]. Ageing, disease, and medicine consumption can cause hair loss, known as alopecia. Although alopecia has no life threatening effects, emotional catchments can lead to psychological disturbance. The available treatments for alopecia include hair transplantation and use of drugs, where drugs are expensive to afford and generation of new hair follicle is challenging. Dermal papillary cells (DPCs), the specialized MSCs localized in hair follicle, are responsible for morphogenesis of hair follicle and hair cycling. The layer-by-layer coating of DPCs, called GAG coating, consists of coating of geletin as outer layer, middle layer of fibroblast growth factor 2 (FGF2) loaded alginate, and innermost layer of geletin. GAG coating creates tissue microenvironment for DPCs that can sustain immunological and mechanical obstacles, supporting generation of hair follicle. Transplantation of GAG-coated DPCs leads to abundant hair growth and maturation of hair follicle, where GAG coating serves as ECM, enhancing intrinsic therapeutic potential of DPCs [58]. During infection, the inflammatory cytokines secreted from host immune cells attract MSCs to the site of inflammation, which modulates inflammatory responses, representing MSCs as key candidate of regenerative medicine for infectious disease therapeutics. Coculture of macrophages $(\mathrm{M} \phi)$ and adipose derived MSCs from Leishmania major (LM) susceptible and resistant mice demonstrates that $\mathrm{AD}$-MSCs educate $\mathrm{M} \phi$ against LM infection, differentially inducing M1 and M2 phenotype that represents AD-MSC as therapeutic agent for leishmanial therapy [93]. In summary, the multilineage differentiation potential of MSCs, as well as adoption of nextgeneration organoid culture system, avails MSCs as ideal regenerative medicine candidate.

\section{UCSCs in Regenerative Medicine}

Umbilical cord, generally thrown at the time of child birth, is the best known source for stem cells, procured in noninvasive manner, having lesser ethical constraints than ESCs.
Umbilical cord is rich source of hematopoietic stem cells (HSCs) and MSCs, which possess enormous regeneration potential [94] (Figure 5; Table 1). The HSCs of cord blood are responsible for constant renewal of all types of blood cells and protective immune cells. The proliferation of HSCs is regulated by Musashi-2 protein mediated attenuation of Aryl hydrocarbon receptor (AHR) signalling in stem cells [95]. UCSCs can be cryopreserved at stem cells banks (Figure 5; Table 1), in operation by both private and public sector organization. Public stem cells banks operate on donation formats and perform rigorous screening for HLA typing and donated UCSCs remain available to anyone in need, whereas private stem cell banks operation is more personalized, availing cells according to donor consent. Stem cell banking is not so common, even in developed countries. Survey studies find that educated women are more eager to donate UCSCs, but willingness for donation decreases with subsequent deliveries, due to associated cost and safety concerns for preservation [96]. FDA has approved five HSCs for treatment of blood and other immunological complications [97]. The amniotic fluid, drawn during pregnancy for standard diagnostic purposes, is generally discarded without considering its vasculogenic potential. UCSCs are the best alternatives for those patients who lack donors with fully matched HLA typing for peripheral blood and PBMCs and bone marrow [98]. One major issue with UCSCs is number of cells in transplant, fewer cells in transplant require more time for engraftment to mature, and there are also risks of infection and mortality; in that case ex vivo propagation of UCSCs can meet the demand of desired outcomes. There are diverse protocols, available for ex vivo expansion of UCSCs, reviewed elsewhere [99]. Amniotic fluid stem cells (AFSCs), coaxed to fibrin (required for blood clotting, ECM interactions, wound healing, and angiogenesis) hydrogel and PEG supplemented with vascular endothelial growth factor (VEGF), give rise to vascularised tissue, when grafted to mice, suggesting that organoid cultures of UCSCs have promise for generation of biocompatible tissue patches, for treating infants born with congenital heart defects [59]. Retroviral integration of OCT4, KLF4, cMYC, and SOX2 transforms AFSCs into pluripotency stem cells known as AFiPSCs which can be directed to differentiate into extraembryonic trophoblast by BMP2 and BMP4 stimulation, which can be used for regeneration of placental tissues [60]. Wharton's jelly (WJ), the gelatinous substance inside umbilical cord, is rich in mucopolysaccharides, fibroblast, macrophages, and stem cells. The stem cells from UCB and WJ can be transdifferentiated into $\beta$-cells. Homogeneous nature of WJSCs enables better differentiation into $\beta$-cells; transplantation of these cells to streptozotocin induced diabetic mice efficiently brings glucose level to normal [7]. Easy access and expansion potential and plasticity to differentiate into multiple cell lineages represent $\mathrm{WJ}$ as an ideal candidate for regenerative medicine but cells viability changes with passages with maximum viable population at 5th-6th passages. So it is suggested to perform controlled expansion of WJ-MSCS for desired regenerative outcomes [9]. Study suggests that $\mathrm{CD} 34^{+}$expression leads to the best regenerative outcomes, with less chance of host-versus-graft rejection. In 
vitro expansion of UCSCs, in presence of StemRegenin-1 (SR1), conditionally expands $\mathrm{CD} 34^{+}$cells [61]. In type I diabetic mellitus (T1DM), T-cell mediated autoimmune destruction of pancreatic $\beta$-cells occurs, which has been considered as tough to treat. Transplantation of WJ-SCs to recent onsetT1DM patients restores pancreatic function, suggesting that WJ-MSCs are effective in regeneration of pancreatic tissue anomalies [62]. WJ-MSCs also have therapeutic importance for treatment of T2DM. A non-placebo controlled phase I/II clinical trial demonstrates that intravenous and intrapancreatic endovascular injection of WJ-MSCs to T2DM patients controls fasting glucose and glycated haemoglobin through improvement of $\beta$-cells functions, evidenced by enhanced cpeptides and reduced inflammatory cytokines (IL-1 $\beta$ and IL6) and T-cells counts [63]. Like diabetes, systematic lupus erythematosus (SLE) also can be treated with WJ-MSCs transplantation. During progression of SLE host immune system targets its own tissue leading to degeneration of renal, cardiovascular, neuronal, and musculoskeletal tissues. A non-placebo controlled follow-up study on 40 SLE patients demonstrates that intravenous infusion of WJ-MSC improves renal functions and decreases systematic lupus erythematosus disease activity index (SLEDAI) and British Isles Lupus Assessment Group (BILAG), and repeated infusion of WJMSCs protects the patient from relapse of the disease [64]. Sometimes, host inflammatory immune responses can be detrimental for HSCs transplantation and blood transfusion procedures. Infusion of WJ-MSC to patients, who had allogenic HSCs transplantation, reduces haemorrhage inflammation (HI) of bladder, suggesting that WJ-MSCs are potential stem cells adjuvant in HSCs transplantation and blood transfusion based therapies [100]. Apart from WJ, umbilical cord perivascular space and cord vein are also rich source for obtaining MSCs. The perivascular MSCs of umbilical cord are more primitive than WJ-MSCs and other MSCs from cord suggest that perivascular MSCs might be used as alternatives for WJ-MSCs for regenerative therapeutics outcome [101]. Based on origin, MSCs exhibit differential in vitro and in vivo properties and advocate functional characterization of MSCs, prior to regenerative applications. Emerging evidence suggests that UCSCs can heal brain injuries, caused by neurodegenerative diseases like Alzheimer's, Krabbe's disease, and so forth. Krabbe's disease, the infantile lysosomal storage disease, occurs due to deficiency of myelin synthesizing enzyme (MSE), affecting brain development and cognitive functions. Progression of neurodegeneration finally leads to death of babies aged two. Investigation shows that healing of peripheral nervous system (PNS) and central nervous system (CNS) tissues with Krabbe's disease can be achieved by allogenic UCSCs. UCSCs transplantation to asymptomatic infants with subsequent monitoring for 4-6 years reveals that UCSCs recover babies from MSE deficiency, improving myelination and cognitive functions, compared to those of symptomatic babies. The survival rate of transplanted UCSCs in asymptomatic and symptomatic infants was $100 \%$ and $43 \%$, respectively, suggesting that early diagnosis and timely treatment are critical for UCSCs acceptance for desired therapeutic outcomes. UCSCs are more primitive than BMSCs, so perfect HLA typing is not critically required, representing UCSCs as an excellent source for treatment of all the diseases involving lysosomal defects, like Krabbe's disease, hurler syndrome, adrenoleukodystrophy (ALD), metachromatic leukodystrophy (MLD), Tay-Sachs disease (TSD), and Sandhoff disease [65]. Brain injuries often lead to cavities formation, which can be treated from neuronal parenchyma, generated ex vivo from UCSCs. Coaxing of UCSCs into human originated biodegradable matrix scaffold and in vitro expansion of cells in defined culture conditions lead to formation of neuronal organoids, within three wks' time frame. These organoids structurally resemble brain tissue and consisted of neuroblasts $\left(\mathrm{GFAP}^{+}, \mathrm{Nestin}^{+}\right.$, and $\mathrm{Ki} 67^{+}$) and immature stem cells $\left(\mathrm{OCT}_{4}{ }^{+}\right.$and $\mathrm{SOX}_{2}{ }^{+}$). The neuroblasts of these organoids further can be differentiated into mature neurons $\left(\mathrm{MAP}^{+}\right.$and $\mathrm{TUJ1}^{+}$) [66]. Administration of high dose of drugs in divesting neuroblastoma therapeutics requires immediate restoration of hematopoiesis. Although BMSCs had been promising in restoration of hematopoiesis UCSCs are sparely used in clinical settings. A case study demonstrates that neuroblastoma patients who received autologous UCSCs survive without any associated side effects [12]. During radiation therapy of neoplasm, spinal cord myelitis can occur, although occurrence of myelitis is a rare event and usually such neurodegenerative complication of spinal cord occurs 6-24 years after exposure to radiations. Transplantation of allogenic UC-MSCs in laryngeal patients undergoing radiation therapy restores myelination [102]. For treatment of neurodegenerative disease like Alzheimer's disease (AD), amyotrophic lateral sclerosis (ALS), traumatic brain injuries (TBI), Parkinson's, SCI, stroke, and so forth, distribution of transplanted UCSCs is critical for therapeutic outcomes. In mice and rat, injection of UCSCs and subsequent MRI scanning show that transplanted UCSCs migrate to CNS and multiple peripheral organs [67]. For immunomodulation of tumor cells disease recovery, transplantation of allogenic DCs

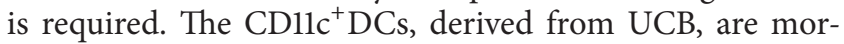
phologically and phenotypically similar to those of peripheral blood derived CTLs-DCs, suggesting that UCB-DCs can be used for personalized medicine of cancer patient, in need for DCs transplantation [103]. Coculture of UCSCs with radiation exposed human lung fibroblast stops their transdifferentiation, which suggests that factors secreted from UCSCs may restore niche identity of fibroblast, if they are transplanted to lung after radiation therapy [104]. Tearing of shoulder cuff tendon can cause severe pain and functional disability, whereas ultrasound guided transplantation of UCB-MSCs in rabbit regenerates subscapularis tendon in four wks' time frame, suggesting that UCB-MSCs are effective enough to treat tendons injuries when injected to focal points of tear-site [68]. Furthermore, transplantation of UCB-MSCs to chondral cartilage injuries site in pig knee along with HA hydrogel composite regenerates hyaline cartilage [69], suggesting that UCB-MSCs are effective regenerative medicine candidate for treating cartilage and ligament injuries. Physiologically circulatory systems of brain, placenta, and lungs are similar. Infusion of UCB-MSCs to preeclampsia (PE) induced hypertension mice reduces the endotoxic effect, suggesting that UC-MSCs are potential source for treatment of endotoxin 
induced hypertension during pregnancy, drug abuse, and other kinds of inflammatory shocks [105]. Transplantation of UCSCs to severe congenital neutropenia (SCN) patients restores neutrophils count from donor cells without any side effect, representing UCSCs as potential alternative for SCN therapy, when HLA matched bone marrow donors are not accessible [106]. In clinical settings, the success of myocardial infarction (MI) treatment depends on ageing, systemic inflammation in host, and processing of cells for infusion. Infusion of human hyaluronan hydrogel coaxed UCSCs in pigs induces angiogenesis, decreases scar area, improves cardiac function at preclinical level, and suggests that the same strategy might be effective for human [107]. In stem cells therapeutics, UCSCs transplantation can be either autologous or allogenic. Sometimes, the autologous UCSCs transplants cannot combat over tumor relapse, observed in Hodgkin's lymphoma (HL), which might require second dose transplantation of allogenic stem cells, but efficacy and tolerance of stem cells transplant need to be addressed, where tumor replace occurs. A case study demonstrates that second dose allogenic transplants of UCSCs effective for HL patients, who had heavy dose in prior transplant, increase the long term survival chances by $30 \%$ [10]. Patients undergoing long term peritoneal renal dialysis are prone to peritoneal fibrosis and can change peritoneal structure and failure of ultrafiltration processes. The intraperitoneal (IP) injection of WJ-MSCs prevents methylglyoxal induced programmed cell death and peritoneal wall thickening and fibrosis, suggesting that WJ-MSCs are effective in therapeutics of encapsulating peritoneal fibrosis [70]. In summary, UCB-HSCs, WJ-MSCs, perivascular MSCs, and UCB-MSCs have tissue regeneration potential.

\section{BMSCs in Regenerative Medicine}

Bone marrow found in soft spongy bones is responsible for formation of all peripheral blood and comprises hematopoietic stem cells (producing blood cells) and stromal cells (producing fat, cartilage, and bones) [108] (Figure 6; Table 1). Visually bone marrow has two types, red marrow (myeloid tissue; producing $\mathrm{RBC}$, platelets, and most of $\mathrm{WBC}$ ) and yellow marrow (producing fat cells and some WBC) [108]. Imbalance in marrow composition can culminate to the diseased condition. Since 1980, bone marrow transplantation is widely accepted for cancer therapeutics [109]. In order to avoid graft rejection, HLA typing of donors is a must, but completely matched donors are limited to family members, which hampers allogenic transplantation applications. Since matching of all HLA antigens is not critically required, in that case defining the critical antigens for haploidentical allogenic donor for patients, who cannot find fully matched donor, might relieve from donor constraints. Two-step administration of lymphoid and myeloid BMSCs from haploidentical donor to the patients of aplastic anaemia and haematological malignancies reconstructs host immune system and the outcomes are almost similar to fully matched transplants, which recommends that profiling of critically important HLA is sufficient for successful outcomes of BMSCs transplantation. Haploidentical HLA matching protocol is the major process for minorities and others who do not have access to matched donor [71]. Furthermore, antigen profiling is not the sole concern for BMSCs based therapeutics. For example, restriction of HIV1 (human immune deficiency virus) infection is not feasible through BMSCs transplantation because HIV1 infection is mediated through $\mathrm{CD} 4^{+}$ receptors, chemokine CXC motif receptor 4 (CXCR4), and chemokine receptor 5 (CCR5) for infecting and propagating into $\mathrm{T}$ helper (Th), monocytes, macrophages, and dendritic cells (DCs). Genetic variation in CCR2 and CCR5 receptors is also a contributory factor; mediating protection against infection has been reviewed elsewhere [110]. Engineering of hematopoietic stem and progenitor cells (HSPCs) derived $\mathrm{CD}^{+}$cells to express HIV1 antagonistic RNA, specifically designed for targeting HIV1 genome, can restrict HIV1 infection, through immune elimination of latently infected $\mathrm{CD}^{+}$cells. A single dose infusion of genetically modified (GM), HIV1 resistant HSPCs can be the alternative of HIV1 retroviral therapy. In the present scenario stem cells source, patient selection, transplantation-conditioning regimen, and postinfusion follow-up studies are the major factors, which can limit application of HIV1 resistant GM-HSPCs $\left(\mathrm{CD} 4^{+}\right)$ cells application in AIDS therapy $[72,73]$. Platelets, essential for blood clotting, are formed from megakaryocytes inside the bone marrow [74]. Due to infection, trauma, and cancer, there are chances of bone marrow failure. To an extent, spongy bone marrow microenvironment responsible for lineage commitment can be reconstructed ex vivo [75]. The ex vivo constructed $3 \mathrm{D}$-scaffolds consisted of microtubule and silk sponge, flooded with chemically defined organ culture medium, which mimics bone marrow environment. The coculture of megakaryocytes and embryonic stem cells (ESCs) in this microenvironment leads to generation of functional platelets from megakaryocytes [75]. The ex vivo 3D-scaffolds of bone microenvironment can stride the path for generation of platelets in therapeutic quantities for regenerative medication of burns [75] and blood clotting associated defects. Accidents, traumatic injuries, and brain stroke can deplete neuronal stem cells (NSCs), responsible for generation of neurons, astrocytes, and oligodendrocytes. Brain does not repopulate NSCs and heal traumatic injuries itself and transplantation of BMSCs also can heal neurodegeneration alone. Lipoic acid (LA), a known pharmacological antioxidant compound used in treatment of diabetic and multiple sclerosis neuropathy when combined with BMSCs, induces neovascularisation at focal cerebral injuries, within $8 \mathrm{wks}$ of transplantation. Vascularisation further attracts microglia and induces their colonization into scaffold, which leads to differentiation of BMSCs to become brain tissue, within 16 wks of transplantation. In this approach, healing of tissue directly depends on number of BMSCs in transplantation dose [76]. Dental caries and periodontal disease are common craniofacial disease, often requiring jaw bone reconstruction after removal of the teeth. Traditional therapy focuses on functional and structural restoration of oral tissue, bone, and teeth rather than biological restoration, but BMSCs based therapies promise for regeneration of craniofacial bone 
defects, enabling replacement of missing teeth in restored bones with dental implants. Bone marrow derived $\mathrm{CD} 14^{+}$ and $\mathrm{CD} 0^{+}$stem and progenitor cells, termed as tissue repair cells (TRC), accelerate alveolar bone regeneration and reconstruction of jaw bone when transplanted in damaged craniofacial tissue, earlier to oral implants. Hence, TRC therapy reduces the need of secondary bone grafts, best suited for severe defects in oral bone, skin, and gum, resulting from trauma, disease, or birth defects [77]. Overall, HSCs have great value in regenerative medicine, where stem cells transplantation strategies explore importance of niche in tissue regeneration. Prior to transplantation of BMSCs, clearance of original niche from target tissue is necessary for generation of organoid and organs without host-versusgraft rejection events. Some genetic defects can lead to disorganization of niche, leading to developmental errors. Complementation with human blastocyst derived primary cells can restore niche function of pancreas in pigs and rats, which defines the concept for generation of clinical grade human pancreas in mice and pigs [111]. Similar to other organs, diaphragm also has its own niche. Congenital defects in diaphragm can affect diaphragm functions. In the present scenario functional restoration of congenital diaphragm defects by surgical repair has risk of reoccurrence of defects or incomplete restoration [8]. Decellularization of donor derived diaphragm offers a way for reconstruction of new and functionally compatible diaphragm through niche modulation. Tissue engineering technology based decellularization of diaphragm and simultaneous perfusion of bone marrow mesenchymal stem cells (BM-MSCs) facilitates regeneration of functional scaffolds of diaphragm tissues [8]. In vivo replacement of hemidiaphragm in rats with reseeded scaffolds possesses similar myography and spirometry as it has in vivo in donor rats. These scaffolds retaining natural architecture are devoid of immune cells, retaining intact extracellular matrix that supports adhesion, proliferation, and differentiation of seeded cells [8]. These findings suggest that cadaver obtained diaphragm, seeded with BM-MSCs, can be used for curing patients in need for restoration of diaphragm functions (Figure 6; Table 1). However, BMSCs are heterogeneous population, which might result in differential outcomes in clinical settings; however clonal expansion of BMSCs yields homogenous cells population for therapeutic application [8]. One study also finds that intracavernous delivery of single clone BMSCs can restore erectile function in diabetic mice [112] and the same strategy might be explored for adult human individuals. The infection of hepatitis $\mathrm{C}$ virus (HCV) can cause liver cirrhosis and degeneration of hepatic tissue. The intraparenchymal transplantation of bone marrow mononuclear cells (BMMNCs) into liver tissue decreases aspartate aminotransferase (AST), alanine transaminase (ALT), bilirubin, CD34, and $\alpha$-SMA, suggesting that transplanted BMSCs restore hepatic functions through regeneration of hepatic tissues [113]. In order to meet the growing demand for stem cells transplantation therapy, donor encouragement is always required [8]. The stem cells donation procedure is very simple; with consent donor gets an injection of granulocyte-colony stimulating factor (G-CSF) that increases BMSCs population. Bone marrow collection is done from hip bone using syringe in 4-5 hrs, requiring local anaesthesia and within a wk time frame donor gets recovered donation associated weakness.

\section{7. iPSCs in Regenerative Medicine}

The field of iPSCs technology and research is new to all other stem cells research, emerging in 2006 when, for the first time, Takahashi and Yamanaka generated ESCs-like cells through genetic incorporation of four factors, Sox2, Oct3/4, Klf4, and c-Myc, into skin fibroblast [3]. Due to extensive nuclear reprogramming, generated iPSCs are indistinguishable from ESCs, for their transcriptome profiling, epigenetic markings, and functional competence [3], but use of retrovirus in transdifferentiation approach has questioned iPSCs technology. Technological advancement has enabled generation of iPSCs from various kinds of adult cells phasing through ESCs or direct transdifferentiation. This section of review outlines most recent advancement in iPSC technology and regenerative applications (Figure 7; Table 1). Using the new edge of iPSCs technology, terminally differentiated skin cells directly can be transformed into kidney organoids [114], which are functionally and structurally similar to those of kidney tissue in vivo. Up to certain extent kidneys heal themselves; however natural regeneration potential cannot meet healing for severe injuries. During kidneys healing process, a progenitor stem cell needs to become 20 types of cells, required for waste excretion, $\mathrm{pH}$ regulation, and restoration of water and electrolytic ions. The procedure for generation of kidney organoids ex vivo, containing functional nephrons, has been identified for human. These ex vivo kidney organoids are similar to fetal first-trimester kidneys for their structure and physiology. Such kidney organoids can serve as model for nephrotoxicity screening of drugs, disease modelling, and organ transplantation. However generation of fully functional kidneys is a far seen event with today's scientific technologies [114]. Loss of neurons in age-related macular degeneration (ARMD) is the common cause of blindness. At preclinical level, transplantation of iPSCs derived neuronal progenitor cells (NPCs) in rat limits progression of disease through generation of 5-6 layers of photoreceptor nuclei, restoring visual acuity [78]. The various approaches of iPSCs mediated retinal regeneration including ARMD have been reviewed elsewhere [79]. Placenta, the cordial connection between mother and developing fetus, gets degenerated in certain pathophysiological conditions. Nuclear programming of OCT4 knock-out (KO) and wild type (WT) mice fibroblast through transient expression of GATA3, EOMES, TFAP2C, and +/- cMYC generates transgene independent trophoblast stem-like cells (iTSCs), which are highly similar to blastocyst derived TSCs for DNA methylation, H3K7ac, nucleosome deposition of H2A.X, and other epigenetic markings. Chimeric differentiation of iTSCs specifically gives rise to haemorrhagic lineages and placental tissue, bypassing pluripotency phase, opening an avenue for generation of fully functional placenta for human [115]. Neurodegenerative disease like Alzheimer's and obstinate epilepsies can degenerate cerebrum, controlling excitatory 
and inhibitory signals of the brain. The inhibitory tones in cerebral cortex and hippocampus are accounted by $\gamma$-amino butyric acid secreting (GABAergic) interneurons (INs). Loss of these neurons often leads to progressive neurodegeneration. Genomic integration of Ascl1, Dlx5, Foxg1, and Lhx6 to mice and human fibroblast transforms these adult cells into GABAergic-INs (iGABA-INs). These cells have molecular signature of telencephalic INs, release GABA, and show inhibition to host granule neuronal activity [81]. Transplantation of these INs in developing embryo cures from genetic and acquired seizures, where transplanted cells disperse and mature into functional neuronal circuits as local INs [82]. Dorsomorphin and SB-431542 mediated inhibition of TGF- $\beta$ and BMP signalling direct transformation of human iPSCs into cortical spheroids. These cortical spheroids consisted of both peripheral and cortical neurons, surrounded by astrocytes, displaying transcription profiling and electrophysiology similarity with developing fetal brain and mature neurons, respectively [83]. The underlying complex biology and lack of clear etiology and genetic reprogramming and difficulty in recapitulation of brain development have barred understanding of pathophysiology of autism spectrum disorder (ASD) and schizophrenia. 3D organoid cultures of ASD patient derived iPSC generate miniature brain organoid, resembling fetal brain few months after gestation. The idiopathic conditions of these organoids are similar with brain of ASD patients; both possess higher inhibitory GABAergic neurons with imbalanced neuronal connection. Furthermore these organoids express forkhead Box G1 (FOXG1) much higher than normal brain tissue, which explains that FOXG1 might be the leading cause of ASD [84]. Degeneration of other organs and tissues also has been reported, like degeneration of lungs which might occur due to tuberculosis infection, fibrosis, and cancer. The underlying etiology for lung degeneration can be explained through organoid culture. Coaxing of iPSC into inert biomaterial and defined culture leads to formation of lung organoids that consisted of epithelial and mesenchymal cells, which can survive in culture for months. These organoids are miniature lung, resemble tissues of large airways and alveoli, and can be used for lung developmental studies and screening of antituberculosis and anticancer drugs [87]. The conventional multistep reprogramming for iPSCs consumes months of time, while CRISPER-Cas9 system based episomal reprogramming system that combines two steps together enables generation of ESCs-like cells in less than two wks, reducing the chances of culture associated genetic abrasions and unwanted epigenetic [80]. This approach can yield single step ESCs-like cells in more personalized way from adults with retinal degradation and infants with severe immunodeficiency, involving correction for genetic mutation of OCT4 and DNMT3B [80]. The iPSCs expressing antiCCR5-RNA, which can be differentiated into HIV1 resistant macrophages, have applications in AIDS therapeutics [88]. The diversified immunotherapeutic application of iPSCs has been reviewed elsewhere [89]. The $\alpha$-1 antitrypsin deficiency (A1AD) encoded by serpin peptidase inhibitor clade A member 1 (SERPINA1) protein synthesized in liver protects lungs from neutrophils elastase, the enzyme causing disruption of lungs connective tissue. A1AD deficiency is common cause of both lung and liver disease like chronic obstructive pulmonary disease (COPD) and liver cirrhosis. Patient specific iPSCs from lung and liver cells might explain pathophysiology of A1AD deficiency. COPD patient derived iPSCs show sensitivity to toxic drugs which explains that actual patient might be sensitive in similar fashion. It is known that A1AD deficiency is caused by single base pair mutation and correction of this mutation fixes the A1AD deficiency in hepatic-iPSCs [85]. The high order brain functions, like emotions, anxiety, sleep, depression, appetite, breathing heartbeats, and so forth, are regulated by serotonin neurons. Generation of serotonin neurons occurs prior to birth, which are postmitotic in their nature. Any sort of developmental defect and degeneration of serotonin neurons might lead to neuronal disorders like bipolar disorder, depression, and schizophrenia-like psychiatric conditions. Manipulation of Wnt signalling in human iPSCs in defined culture conditions leads to an in vitro differentiation of iPSCs to serotoninlike neurons. These iPSCs-neurons primarily localize to rhombomere 2-3 segment of rostral raphe nucleus, exhibit electrophysiological properties similar to serotonin neurons, express hydroxylase 2 , the developmental marker, and release serotonin in dose and time dependent manner. Transplantation of these neurons might cure from schizophrenia, bipolar disorder, and other neuropathological conditions [116]. The iPSCs technology mediated somatic cell reprogramming of ventricular monocytes results in generation of cells, similar in morphology and functionality with PCs. SA note transplantation of PCs to large animals improves rhythmic heart functions. Pacemaker needs very reliable and robust performance so understanding of transformation process and site of transplantation are the critical aspect for therapeutic validation of iPSCs derived PCs [28]. Diabetes is a major health concern in modern world, and generation of $\beta$ cells from adult tissue is challenging. Direct reprogramming of skin cells into pancreatic cells, bypassing pluripotency phase, can yield clinical grade $\beta$-cells. This reprogramming strategy involves transformation of skin cells into definitive endodermal progenitors ( $\mathrm{cDE}$ ) and foregut like progenitor cells $(\mathrm{cPF})$ intermediates and subsequent in vitro expansion of these intermediates to become pancreatic $\beta$-cells (cPB). The first step is chemically complex and can be understood as nonepisomal reprogramming on day one with pluripotency factors (OCT4, SOX2, KLF4, and hair pin RNA against p53), then supplementation with GFs and chemical supplements on day seven (EGF, bFGF, CHIR, NECA, NaB, Par, and $\mathrm{RG}$ ), and two weeks later (Activin-A, CHIR, NECA, NaB, and $\mathrm{RG}$ ) yielding $\mathrm{DE}$ and $\mathrm{CPF}$ [86]. Transplantation of $\mathrm{cPB}$ yields into glucose stimulated secretion of insulin in diabetic mice defines that such cells can be explored for treatment of T1DM and T2DM in more personalized manner [86]. iPSCs represent underrated opportunities for drug industries and clinical research laboratories for development of therapeutics, but safety concerns might limit transplantation applications (Figure 7; Table 1) [117]. Transplantation of human iPSCs into mice gastrula leads to colonization and differentiation of cells into three germ layers, evidenced with clinical developmental fat measurements. The acceptance of human iPSCs by mice 
gastrula suggests that correct timing and appropriate reprogramming regime might delimit human mice species barrier. Using this fact of species barrier, generation of human organs in closely associated primates might be possible, which can be used for treatment of genetic factors governed disease at embryo level itself [118]. In summary, iPSCs are safe and effective for treatment of regenerative medicine.

\section{Stem Cells in Wildlife Conservation}

The unstable growth of human population threatens the existence of wildlife, through overexploitation of natural habitats and illegal killing of wild animals, leading many species to face the fate of being endangered and go for extinction. For wildlife conservation, the concept of creation of frozen zoo involves preservation of gene pool and germ plasm from threatened and endangered species (Figure 8). The frozen zoo tissue samples collection from dead or live animal can be DNA, sperms, eggs, embryos, gonads, skin, or any other tissue of the body [119]. Preserved tissue can be reprogrammed or transdifferentiated to become other types of tissues and cells, which opens an avenue for conservation of endangered species and resurrection of life (Figure 8). The gonadal tissue from young individuals harbouring immature tissue can be matured in vivo and ex vivo for generation of functional gametes. Transplantation of SSCs to testis of male from the same different species can give rise to spermatozoa of donor cells [120], which might be used for IVF based captive breeding of wild animals. The most dangerous fact in wildlife conservation is low genetic diversity, too few reproductively capable animals which cannot maintain adequate genetic diversity in wild or captivity. Using the edge of iPSC technology, pluripotent stem cells can be generated from skin cells. For endangered drill, Mandrillus leucophaeus, and nearly extinct white rhinoceros, Ceratotherium simum cottoni, iPSC has been generated in 2011 [121]. The endangered animal drill (Mandrillus leucophaeus) is genetically very close to human and often suffers from diabetes, while rhinos are genetically far removed from other primates. The progress in iPSCs, from the human point of view, might be transformed for animal research for recapturing reproductive potential and health in wild animals. However, stem cells based interventions in wild animals are much more complex than classical conservation planning and biomedical research has to face. Conversion of iPSC into egg or sperm can open the door for generation of IVF based embryo; those might be transplanted in womb of live counterparts for propagation of population. Recently, iPSCs have been generated for snow leopard (Panthera uncia), native to mountain ranges of central Asia, which belongs to cat family; this breakthrough has raised the possibilities for cryopreservation of genetic material for future cloning and other assisted reproductive technology (ART) applications, for the conservation of cat species and biodiversity. Generation of leopard iPSCs has been achieved through retroviral-system based genomic integration of OCT4, SOX2, KLF4, cMYC, and NANOG. These iPSCs from snow leopard also open an avenue for further transformation of iPSCs into gametes [122]. The in vivo maturation of grafted tissue depends both on age and on hormonal status of donor tissue. These facts are equally applicable to accepting host. Ectopic xenografts of cryopreserved testis tissue from Indian spotted deer (Moschiola indica) to nude mice yielded generation of spermatocytes [123], suggesting that one-day procurement of functional sperm from premature tissue might become a general technique in wildlife conservation. In summary, tissue biopsies from dead or live animals can be used for generation of iPSCs and functional gametes; those can be used in assisted reproductive technology (ART) for wildlife conservation.

\section{Future Perspectives}

The spectacular progress in the field of stem cells research represents great scope of stem cells regenerative therapeutics. It can be estimated that by 2020 or so we will be able to produce wide array of tissue, organoid, and organs from adult stem cells. Inductions of pluripotency phenotypes in terminally differentiated adult cells have better therapeutic future than ESCs, due to least ethical constraints with adult cells. In the coming future, there might be new pharmaceutical compounds; those can activate tissue specific stem cells, promote stem cells to migrate to the side of tissue injury, and promote their differentiation to tissue specific cells. Except few countries, the ongoing financial and ethical hindrance on ESCs application in regenerative medicine have more chance for funding agencies to distribute funding for the least risky projects on UCSCs, BMSCs, and TSPSCs from biopsies. The existing stem cells therapeutics advancements are more experimental and high in cost; due to that application on broad scale is not feasible in current scenario. In the near future, the advancements of medical science presume using stem cells to treat cancer, muscles damage, autoimmune disease, and spinal cord injuries among a number of impairments and diseases. It is expected that stem cells therapies will bring considerable benefits to the patients suffering from wide range of injuries and disease. There is high optimism for use of BMSCs, TSPSCs, and iPSCs for treatment of various diseases to overcome the contradictions associated with ESCs. For advancement of translational application of stem cells, there is a need of clinical trials, which needs funding rejoinder from both public and private organizations. The critical evaluation of regulatory guidelines at each phase of clinical trial is a must to comprehend the success and efficacy in time frame.

\section{Abbreviations}

ESCs: $\quad$ Embryonic stem cells

TSPSCs: Tissue specific progenitor stem cells

UCSCs: Umbilical cord stem cells

BMSCs: Bone marrow stem cells

iPSCs: Induced pluripotent stem cells

MSCs: Mesenchymal stem cells

WJ-MSCs: Wharton's jelly mesenchymal stem cells

HSCs: Hematopoietic stem cells 


\begin{tabular}{|c|c|}
\hline RGCs: & Retinal ganglion cells \\
\hline T1DM: & Type I diabetes mellitus \\
\hline T2DM: & Type 2 diabetes mellitus \\
\hline A1AD: & $\alpha-1$ antitrypsin deficiency \\
\hline COPD: & Chronic obstructive pulmonary disease \\
\hline HLA: & Human leukocyte antigen \\
\hline MHC: & Major histocompatibility complex \\
\hline 3D: & Three-dimensional \\
\hline SCI: & Spinal cord injury \\
\hline ARMD: & Age-related macular degeneration \\
\hline RPE: & Retinal pigment epithelium \\
\hline PXR: & Pregnane X receptor \\
\hline DPSCs: & Dental pulp stem cells \\
\hline GFAP: & Glial fibrillary acidic protein \\
\hline Atoh1: & $\begin{array}{l}\text { Activation of transcription factor atonal } \\
\text { homologue } 1\end{array}$ \\
\hline NEC: & Necrotizing enterocolitis \\
\hline DMD: & Duchene muscular dystrophy \\
\hline PDGF: & Placental derived growth factor \\
\hline PEG: & Polyethylene glycol \\
\hline SSCs: & Spermatogonial stem cells \\
\hline AdSCs: & Adipose derived stem cells \\
\hline HSCs: & Hematopoietic stem cells \\
\hline AFSCs: & Amniotic fluid stem cells \\
\hline VEGF: & Vascular endothelial growth factor \\
\hline UCB: & Umbilical cord blood \\
\hline SLEDAI: & $\begin{array}{l}\text { Systematic lupus erythematosus (SLE) dis- } \\
\text { ease activity index }\end{array}$ \\
\hline HIV-1: & Human immunodeficiency virus-1 \\
\hline GM-HSPCs: & $\begin{array}{l}\text { Genetically modified hematopoietic stem } \\
\text { and progenitor cells }\end{array}$ \\
\hline Th: & T helper \\
\hline LA: & Lipoic acid \\
\hline TRC: & Tissue repair cells \\
\hline BM-MSCs: & Bone marrow mesenchymal stem cells \\
\hline PBSCs: & Peripheral blood stem cells \\
\hline G-CSF: & Granulocyte-colony stimulating factor \\
\hline SERPINA1: & $\begin{array}{l}\text { Serpin peptidase inhibitor clade A member } \\
1\end{array}$ \\
\hline ASD: & Autism spectrum disorder \\
\hline INs: & Interneurons \\
\hline GABAergic: & $\Upsilon$-amino butyric acid secreting \\
\hline NPCs: & Neuronal progenitor cells \\
\hline iTSCs: & Independent trophoblast stem-like cells \\
\hline hCS: & Human cortical spheroids \\
\hline CMs: & Cardiomyocytes \\
\hline ALD: & Adrenoleukodystrophy \\
\hline MLD: & Metachromatic leukodystrophy \\
\hline TSD: & Tay-Sachs disease \\
\hline ALS: & Amyotrophic lateral sclerosis \\
\hline TBI: & Traumatic brain injuries \\
\hline AD: & Alzheimer's disease \\
\hline NSCs: & Neuronal stem cells \\
\hline SID: & Severe immune deficiency. \\
\hline
\end{tabular}

\section{Competing Interests}

There are no competing interests associated with this paper.

\section{Acknowledgments}

Dr. Anuradha Reddy from Centre for Cellular and Molecular Biology Hyderabad and Mrs. Sarita Kumari from Department of Yoga Science, BU, Bhopal, India, are acknowledged for their critical suggestions and comments on paper.

\section{References}

[1] C. Mason and P. Dunnill, "A brief definition of regenerative medicine," Regenerative Medicine, vol. 3, no. 1, pp. 1-5, 2008.

[2] L. A. Fortier, "Stem cells: classifications, controversies, and clinical applications," Veterinary Surgery, vol. 34, no. 5, pp. 415423, 2005.

[3] K. Takahashi and S. Yamanaka, "Induction of pluripotent stem cells from mouse embryonic and adult fibroblast cultures by defined factors," Cell, vol. 126, no. 4, pp. 663-676, 2006.

[4] J. Yu, M. A. Vodyanik, K. Smuga-Otto et al., "Induced pluripotent stem cell lines derived from human somatic cells," Science, vol. 318, no. 5858, pp. 1917-1920, 2007.

[5] M. Thomson, S. J. Liu, L.-N. Zou, Z. Smith, A. Meissner, and S. Ramanathan, "Pluripotency factors in embryonic stem cells regulate differentiation into germ layers," Cell, vol. 145, no. 6, pp. 875-889, 2011.

[6] E. W. Petersdorf, M. Malkki, T. A. Gooley, P. J. Martin, and Z. Guo, "MHC haplotype matching for unrelated hematopoietic cell transplantation," PLoS Medicine, vol. 4, no. 1, article e8, 2007.

[7] A. M. Leferink, Y. C. Chng, C. A. van Blitterswijk, and L. Moroni, "Distribution and viability of fetal and adult human bone marrow stromal cells in a biaxial rotating vessel bioreactor after seeding on polymeric 3D additive manufactured scaffolds," Frontiers in Bioengineering and Biotechnology, vol. 3, article 169, 2015.

[8] E. A. Gubareva, S. Sjöqvist, I. V. Gilevich et al., "Orthotopic transplantation of a tissue engineered diaphragm in rats," Biomaterials, vol. 77, pp. 320-335, 2016.

[9] I. Garzón, B. Pérez-Köhler, J. Garrido-Gómez et al., "Evaluation of the cell viability of human Wharton's Jelly stem cells for use in cell therapy," Tissue Engineering Part C: Methods, vol. 18, no. 6, pp. 408-419, 2012.

[10] P. A. Thompson, T. Perera, D. Marin et al., "Double umbilical cord blood transplant is effective therapy for relapsed or refractory Hodgkin lymphoma," Leukemia \& Lymphoma, vol. 57, no. 7, pp. 1607-1615, 2016.

[11] S. S. Nathamgari, B. Dong, F. Zhou et al., "Isolating single cells in a neurosphere assay using inertial microfluidics," Lab on a Chip-Miniaturisation for Chemistry and Biology, vol. 15, no. 24, pp. 4591-4597, 2015.

[12] B. Ning, D. K. Cheuk, A. K. Chiang, P. P. Lee, S. Y. Ha, and G. C. Chan, "Autologous cord blood transplantation for metastatic neuroblastoma," Pediatric Transplantation, vol. 20, no. 2, pp. 290-296, 2015.

[13] J. A. Thomson, "Embryonic stem cell lines derived from human blastocysts," Science, vol. 282, no. 5391, pp. 1145-1147, 1998.

[14] M. S. Hogan, D.-E. Parfitt, C. J. Zepeda-Mendoza, M. M. Shen, and D. L. Spector, "Transient pairing of homologous Oct4 alleles accompanies the onset of embryonic stem cell differentiation," Cell Stem Cell, vol. 16, no. 3, pp. 275-288, 2015.

[15] G. Shroff and R. Gupta, "Human embryonic stem cells in the treatment of patients with spinal cord injury," Annals of Neurosciences, vol. 22, no. 4, pp. 208-216, 2015. 
[16] S. Zhou, A. Flamier, M. Abdouh et al., "Differentiation of human embryonic stem cells into cone photoreceptors through simultaneous inhibition of BMP, TGF $\beta$ and Wnt signaling," Development, vol. 142, no. 19, pp. 3294-3306, 2015.

[17] V. M. Sluch, C.-H. O. Davis, V. Ranganathan et al., "Differentiation of human ESCs to retinal ganglion cells using a CRISPR engineered reporter cell line," Scientific Reports, vol. 5, Article ID 16595, 2015.

[18] Y. Shiba, S. Fernandes, W.-Z. Zhu et al., "Human ES-cell-derived cardiomyocytes electrically couple and suppress arrhythmias in injured hearts," Nature, vol. 489, no. 7415, pp. 322-325, 2012.

[19] S. Fernandes, J. J. H. Chong, S. L. Paige et al., "Comparison of human embryonic stem cell-derived cardiomyocytes, cardiovascular progenitors, and bone marrow mononuclear cells for cardiac repair," Stem Cell Reports, vol. 5, no. 5, pp. 753-762, 2015.

[20] Y. Avior, G. Levy, M. Zimerman et al., "Microbial-derived lithocholic acid and vitamin $\mathrm{K}_{2}$ drive the metabolic maturation of pluripotent stem cells-derived and fetal hepatocytes," Нераtology, vol. 62, no. 1, pp. 265-278, 2015.

[21] K. Cameron, B. Lucendo-Villarin, D. Szkolnicka, and D. C. Hay, "Serum-free directed differentiation of human embryonic stem cells to hepatocytes," Methods in Molecular Biology, vol. 1250, pp. 105-111, 2015.

[22] M. Zhang, P. Sun, Y. Wang et al., "Generation of self-renewing hepatoblasts from human embryonic stem cells by chemical approaches," Stem Cells Translational Medicine, vol. 4, no. 11, pp. 1275-1282, 2015.

[23] L. Tolosa, J. Caron, Z. Hannoun et al., "Transplantation of hESC-derived hepatocytes protects mice from liver injury," Stem Cell Research \& Therapy, vol. 6, article 246, 2015.

[24] A. Carpentier, I. Nimgaonkar, V. Chu, Y. Xia, Z. Hu, and T. J. Liang, "Hepatic differentiation of human pluripotent stem cells in miniaturized format suitable for high-throughput screen," Stem Cell Research, vol. 16, no. 3, pp. 640-650, 2016.

[25] J. E. Bruin, N. Saber, N. Braun et al., "Treating diet-induced diabetes and obesity with human embryonic stem cell-derived pancreatic progenitor cells and antidiabetic drugs," Stem Cell Reports, vol. 4, no. 4, pp. 605-620, 2015.

[26] C. Salguero-Aranda, R. Tapia-Limonchi, and G. M. Cahuana, "Differentiation of mouse embryonic stem cells towards functional pancreatic beta-cell surrogates through epigenetic regulation of Pdxl by nitric oxide," Cell Transplantation, 2016.

[27] A. Cheng, Z. Kapacee, J. Peng et al., "Cartilage repair using human embryonic stem cell-derived chondroprogenitors," Stem Cells Translational Medicine, vol. 3, no. 11, pp. 1287-1295, 2014.

[28] V. Vedantham, "New approaches to biological pacemakers: links to sinoatrial node development," Trends in Molecular Medicine, vol. 21, no. 12, pp. 749-761, 2015.

[29] C. Greggio, F. De Franceschi, M. Figueiredo-Larsen et al., "Artificial three-dimensional niches deconstruct pancreas development in vitro," Development, vol. 140, no. 21, pp. 4452-4462, 2013.

[30] L. Ye, M. A. Robertson, T. L. Mastracci, and R. M. Anderson, "An insulin signaling feedback loop regulates pancreas progenitor cell differentiation during islet development and regeneration," Developmental Biology, vol. 409, no. 2, pp. 354-369, 2016.

[31] P. D. Potdar and Y. D. Jethmalani, "Human dental pulp stem cells: applications in future regenerative medicine," World Journal of Stem Cells, vol. 7, no. 5, pp. 839-851, 2015.

[32] K. M. Ellis, D. C. O'Carroll, M. D. Lewis, G. Y. Rychkov, and S. A. Koblar, "Neurogenic potential of dental pulp stem cells isolated from murine incisors," Stem Cell Research \& Therapy, vol. 5, article 30, 2014.

[33] M. M. Acharya, V. Martirosian, N. N. Chmielewski et al., "Stem cell transplantation reverses chemotherapy-induced cognitive dysfunction," Cancer Research, vol. 75, no. 4, pp. 676-686, 2015.

[34] K. Mizutari, M. Fujioka, M. Hosoya et al., "Notch inhibition induces cochlear hair cell regeneration and recovery of hearing after acoustic trauma," Neuron, vol. 77, no. 1, pp. 58-69, 2013.

[35] B. R. Kuo, E. M. Baldwin, W. S. Layman, M. M. Taketo, and J. Zuo, "In vivo cochlear hair cell generation and survival by coactivation of $\beta$-catenin and Atohl," The Journal of Neuroscience, vol. 35, no. 30, pp. 10786-10798, 2015.

[36] S. A. Shaffiey, H. Jia, T. Keane et al., "Intestinal stem cell growth and differentiation on a tubular scaffold with evaluation in small and large animals," Regenerative Medicine, vol. 11, no. 1, pp. 4561, 2016.

[37] D. H. Scoville, T. Sato, X. C. He, and L. Li, "Current view: intestinal stem cells and signaling," Gastroenterology, vol. 134, no. 3, pp. 849-864, 2008.

[38] X. Yin, H. F. Farin, J. H. Van Es, H. Clevers, R. Langer, and J. M. Karp, "Niche-independent high-purity cultures of $\operatorname{Lgr}^{+}$ intestinal stem cells and their progeny," Nature Methods, vol. 11, no. 1, pp. 106-112, 2014.

[39] B. R. Ksander, P. E. Kolovou, B. J. Wilson et al., "ABCB5 is a limbal stem cell gene required for corneal development and repair," Nature, vol. 511, no. 7509, pp. 353-357, 2014.

[40] S. Ahmad, "Concise review: limbal stem cell deficiency, dysfunction, and distress," Stem Cells Translational Medicine, vol. 1, no. 2, pp. 110-115, 2012.

[41] C. Fuoco, R. Rizzi, A. Biondo et al., "In vivo generation of a mature and functional artificial skeletal muscle," EMBO Molecular Medicine, vol. 7, no. 4, pp. 411-422, 2015.

[42] S. E. Berry, "Concise review: mesoangioblast and mesenchymal stem cell therapy for muscular dystrophy: progress, challenges, and future directions," Stem Cells Translational Medicine, vol. 4, no. 1, pp. 91-98, 2015.

[43] L. Simon, G. C. Ekman, N. Kostereva et al., "Direct transdifferentiation of stem/progenitor spermatogonia into reproductive and nonreproductive tissues of all germ layers," Stem Cells, vol. 27, no. 7, pp. 1666-1675, 2009.

[44] S. M. Cronk, M. R. Kelly-Goss, H. C. Ray et al., "Adiposederived stem cells from diabetic mice show impaired vascular stabilization in a murine model of diabetic retinopathy," Stem Cells Translational Medicine, vol. 4, no. 5, pp. 459-467, 2015.

[45] B. Mead, M. Berry, A. Logan, R. A. H. Scott, W. Leadbeater, and B. A. Scheven, "Stem cell treatment of degenerative eye disease," Stem Cell Research, vol. 14, no. 3, pp. 243-257, 2015.

[46] M. Kessler, K. Hoffmann, V. Brinkmann et al., "The Notch and Wnt pathways regulate stemness and differentiation in human fallopian tube organoids," Nature Communications, vol. 6, article 8989, 2015.

[47] H. Nagata, M. Ii, E. Kohbayashi, M. Hoshiga, T. Hanafusa, and M. Asahi, "Cardiac adipose-derived stem cells exhibit high differentiation potential to cardiovascular cells in C57BL/6 mice," Stem Cells Translational Medicine, vol. 5, no. 2, pp. 141151, 2016.

[48] L. Chen, F. Qin, M. Ge, Q. Shu, and J. Xu, "Application of adipose-derived stem cells in heart disease," Journal of Cardiovascular Translational Research, vol. 7, no. 7, pp. 651-663, 2014.

[49] S. K. Steinbach and M. Husain, "Vascular smooth muscle cell differentiation from human stem/progenitor cells," Methods, vol. 101, pp. 85-92, 2016. 
[50] M. Dominici, K. Le Blanc, I. Mueller et al., "Minimal criteria for defining multipotent mesenchymal stromal cells. The International Society for Cellular Therapy position statement," Cytotherapy, vol. 8, no. 4, pp. 315-317, 2006.

[51] A. K. Sharma, M. I. Bury, A. J. Marks et al., "A nonhuman primate model for urinary bladder regeneration using autologous sources of bone marrow-derived mesenchymal stem cells," STEM CELLS, vol. 29, no. 2, pp. 241-250, 2011.

[52] M. Oshima and T. Tsuji, "Whole tooth regeneration as a future dental treatment," Advances in Experimental Medicine and Biology, vol. 881, pp. 255-269, 2015.

[53] C. Csaki, U. Matis, A. Mobasheri, H. Ye, and M. Shakibaei, "Chondrogenesis, osteogenesis and adipogenesis of canine mesenchymal stem cells: a biochemical, morphological and ultrastructural study," Histochemistry and Cell Biology, vol. 128, no. 6, pp. 507-520, 2007.

[54] I. Ribitsch, J. Burk, U. Delling et al., "Basic science and clinical application of stem cells in veterinary medicine," Advances in Biochemical Engineering/Biotechnology, vol. 123, pp. 219-263, 2010.

[55] B. Sen, Z. Xie, G. Uzer et al., "Intranuclear actin regulates osteogenesis," STEM CELLS, vol. 33, no. 10, pp. 3065-3076, 2015.

[56] S. G. Brown, R. J. Harman, and L. L. Black, "Adipose-derived stem cell therapy for severe muscle tears in working German shepherds: two case reports," Stem Cell Discovery, vol. 2, no. 2, pp. 41-44, 2012.

[57] R. D. Levit, N. Landázuri, E. A. Phelps et al., "Cellular encapsulation enhances cardiac repair," Journal of the American Heart Association, vol. 2, no. 5, Article ID e000367, 2013.

[58] B.-J. Lin, J. Wang, Y. Miao et al., "Cytokine loaded layer-bylayer ultrathin matrices to deliver single dermal papilla cells for spot-by-spot hair follicle regeneration," Journal of Materials Chemistry B, vol. 4, no. 3, pp. 489-504, 2016.

[59] O. M. Benavides, A. R. Brooks, S. K. Cho, J. Petsche Connell, R. Ruano, and J. G. Jacot, "In situ vascularization of injectable fibrin/poly(ethylene glycol) hydrogels by human amniotic fluidderived stem cells," Journal of Biomedical Materials Research Part A, vol. 103, no. 8, pp. 2645-2653, 2015.

[60] K. Wolfrum, Y. Wang, A. Prigione, K. Sperling, H. Lehrach, and J. Adjaye, "The LARGE principle of cellular reprogramming: lost, acquired and retained gene expression in foreskin and amniotic fluid-derived human iPS cells," PLoS ONE, vol. 5, no. 10, Article ID e13703, 2010.

[61] J. E. Wagner Jr., C. G. Brunstein, A. E. Boitano et al., "Phase I/II trial of stemregenin-1 expanded umbilical cord blood hematopoietic stem cells supports testing as a stand-alone graft," Cell Stem Cell, vol. 18, no. 1, pp. 144-155, 2016.

[62] J. Hu, X. Yu, Z. Wang et al., "Long term effects of the implantation of Wharton's jelly-derived mesenchymal stem cells from the umbilical cord for newly-onset type 1 diabetes mellitus," Endocrine Journal, vol. 60, no. 3, pp. 347-357, 2013.

[63] X. Liu, P. Zheng, X. Wang et al., "A preliminary evaluation of efficacy and safety of Wharton's jelly mesenchymal stem cell transplantation in patients with type 2 diabetes mellitus," Stem Cell Research \& Therapy, vol. 5, no. 2, article 57, 2014.

[64] D. Wang, J. Li, Y. Zhang et al., "Umbilical cord mesenchymal stem cell transplantation in active and refractory systemic lupus erythematosus: A Multicenter Clinical Study," Arthritis Research and Therapy, vol. 16, no. 2, article R79, 2014.

[65] M. L. Escolar, M. D. Poe, J. M. Provenzale et al., "Transplantation of umbilical-cord blood in babies with infantile Krabbe's disease," The New England Journal of Medicine, vol. 352, no. 20, pp. 2069-2081, 2005.

[66] M. Jurga, A. W. Lipkowski, B. Lukomska et al., "Generation of functional neural artificial tissue from human umbilical cord blood stem cells," Tissue Engineering Part C: Methods, vol. 15, no. 3, pp. 365-372, 2009.

[67] J. Ehrhart, D. Darlington, N. Kuzmin-Nichols et al., "Biodistribution of infused human umbilical cord blood cells in Alzheimer's disease-like murine model," Cell Transplantation, vol. 25, no. 1, pp. 195-199, 2016.

[68] G.-Y. Park, D. R. Kwon, and S. C. Lee, "Regeneration of full-thickness rotator cuff tendon tear after ultrasound-guided injection with umbilical cord blood-derived mesenchymal stem cells in a Rabbit model," Stem Cells Translational Medicine, vol. 4, no. 11, pp. 1344-1351, 2015.

[69] C.-W. Ha, Y.-B. Park, J.-Y. Chung, and Y.-G. Park, "Cartilage repair using composites of human umbilical cord blood-derived mesenchymal stem cells and hyaluronic acid hydrogel in a minipig model," Stem Cells Translational Medicine, vol. 4, no. 9, pp. 1044-1051, 2015.

[70] Y. P. Fan, C. Hsia, K. Tseng et al., "The therapeutic potential of human umbilical mesenchymal stem cells from Wharton's jelly in the treatment of rat peritoneal dialysis-induced fibrosis," Stem Cells Translational Medicine, vol. 5, no. 2, pp. 235-247, 2016.

[71] S. Gaballa, N. Palmisiano, O. Alpdogan et al., "A two-step haploidentical versus a two-step matched related allogeneic myeloablative peripheral blood stem cell transplantation," Biology of Blood and Marrow Transplantation, vol. 22, no. 1, pp. 141$148,2016$.

[72] D. L. DiGiusto, R. Stan, A. Krishnan, H. Li, J. J. Rossi, and J. A. Zaia, "Development of hematopoietic stem cell based gene therapy for HIV-1 infection: considerations for proof of concept studies and translation to standard medical practice," Viruses, vol. 5, no. 11, pp. 2898-2919, 2013.

[73] E. Herrera-Carrillo and B. Berkhout, "Bone marrow gene therapy for HIV/AIDS," Viruses, vol. 7, no. 7, pp. 3910-3936, 2015.

[74] K. R. Machlus and J. E. Italiano Jr., "The incredible journey: from megakaryocyte development to platelet formation," The Journal of Cell Biology, vol. 201, no. 6, pp. 785-796, 2013.

[75] C. A. Di Buduo, L. S. Wray, L. Tozzi et al., "Programmable 3D silk bone marrow niche for platelet generation ex vivo and modeling of megakaryopoiesis pathologies," Blood, vol. 125, no. 14, pp. 2254-2264, 2015.

[76] S. Paradells, I. Zipancic, M. M. Martínez-Losa et al., "Lipoic acid and bone marrow derived cells therapy induce angiogenesis and cell proliferation after focal brain injury," Brain Injury, vol. 29, no. 3, pp. 380-395, 2015.

[77] D. Kaigler, G. Pagni, C. H. Park et al., "Stem cell therapy for craniofacial bone regeneration: a randomized, controlled feasibility trial," Cell Transplantation, vol. 22, no. 5, pp. 767-777, 2013.

[78] Y. Tsai, B. Lu, B. Bakondi et al., "Human iPSC-derived neural progenitors preserve vision in an AMD-like model," STEM CELLS, vol. 33, no. 8, pp. 2537-2549, 2015.

[79] J. Yang, B. Cai, P. Glencer, Z. Li, X. Zhang, and X. Li, "Induced pluripotent stem cells and outer retinal disease," Stem Cells International, vol. 2016, Article ID 2850873, 6 pages, 2016.

[80] S. E. Howden, J. P. Maufort, B. M. Duffin, A. G. Elefanty, E. G. Stanley, and J. A. Thomson, "Simultaneous reprogramming and 
gene correction of patient fibroblasts," Stem Cell Reports, vol. 5, no. 6, pp. 1109-1118, 2015.

[81] G. Colasante, G. Lignani, A. Rubio et al., "Rapid conversion of fibroblasts into functional forebrain GABAergic interneurons by direct genetic reprogramming," Cell Stem Cell, vol. 17, no. 6, pp. 719-734, 2015.

[82] R. F. Hunt and S. C. Baraban, "Interneuron transplantation as a treatment for epilepsy," Cold Spring Harbor Perspectives in Medicine, vol. 5, no. 12, Article ID a022376, 2015.

[83] A. M. Pasca, S. A. Sloan, L. E. Clarke et al., "Functional cortical neurons and astrocytes from human pluripotent stem cells in 3D culture," Nature Methods, vol. 12, no. 7, pp. 671-678, 2015.

[84] J. Mariani, G. Coppola, P. Zhang et al., "FOXG1-dependent dysregulation of GABA/glutamate neuron differentiation in autism spectrum disorders," Cell, vol. 162, no. 2, pp. 375-390, 2015.

[85] A. A. Wilson, L. Ying, M. Liesa et al., "Emergence of a stage-dependent human liver disease signature with directed differentiation of alpha-1 antitrypsin-deficient iPS cells," Stem Cell Reports, vol. 4, no. 5, pp. 873-885, 2015.

[86] S. Zhu, H. A. Russ, X. Wang et al., "Human pancreatic beta-like cells converted from fibroblasts," Nature Communications, vol. 7, Article ID 10080, 2016.

[87] B. R. Dye, D. R. Hill, M. A. Ferguson et al., "In vitro generation of human pluripotent stem cell derived lung organoids," eLife, vol. 4, Article ID e05098, pp. 1-25, 2015.

[88] A. Kambal, G. Mitchell, W. Cary et al., "Generation of HIV-1 resistant and functional macrophages from hematopoietic stem cell-derived induced pluripotent stem cells," Molecular Therapy, vol. 19, no. 3, pp. 584-593, 2011.

[89] Z. Jiang, Y. Han, and X. Cao, "Induced pluripotent stem cell (iPSCs) and their application in immunotherapy," Cellular and Molecular Immunology, vol. 11, no. 1, pp. 17-24, 2014.

[90] T. Squillaro, G. Peluso, and U. Galderisi, "Clinical trials with mesenchymal stem cells: an update," Cell Transplantation, vol. 25, no. 5, pp. 829-848, 2016.

[91] V. Volarevic, J. Nurkovic, N. Arsenijevic, and M. Stojkovic, "Concise review: therapeutic potential of mesenchymal stem cells for the treatment of acute liver failure and cirrhosis," STEM CELLS, vol. 32, no. 11, pp. 2818-2823, 2014.

[92] S. Patel, P. T. Yin, H. Sugiyama, and K.-B. Lee, "Inducing stem cell myogenesis using nanoscript," ACS Nano, vol. 9, no. 7, pp. 6909-6917, 2015.

[93] S. Dameshghi, A. Zavaran-Hosseini, S. Soudi, F. J. Shirazi, S. Nojehdehi, and S. M. Hashemi, "Mesenchymal stem cells alter macrophage immune responses to Leishmania major infection in both susceptible and resistance mice," Immunology Letters, vol. 170, pp. 15-26, 2016.

[94] S. Shahrokhi, F. Menaa, K. Alimoghaddam, C. McGuckin, and M. Ebtekar, "Insights and hopes in umbilical cord blood stem cell transplantations," Journal of Biomedicine and Biotechnology, vol. 2012, Article ID 572821, 11 pages, 2012.

[95] S. Rentas, N. T. Holzapfel, M. S. Belew et al., "Musashi-2 attenuates AHR signalling to expand human haematopoietic stem cells," Nature, vol. 532, no. 7600, pp. 508-511, 2016.

[96] H. Lu, Y. Chen, Q. Lan et al., "Factors that influence a mother's willingness to preserve umbilical cord blood: a survey of 5120 Chinese mothers," PLoS ONE, vol. 10, no. 12, Article ID e0144001, 2015.

[97] A. Rosemann, "Why regenerative stem cell medicine progresses slower than expected," Journal of Cellular Biochemistry, vol. 115, no. 12, pp. 2073-2076, 2014.
[98] E. Gluckman, G. Koegler, and V. Rocha, "Human leukocyte antigen matching in cord blood transplantation," Seminars in Hematology, vol. 42, no. 2, pp. 85-90, 2005.

[99] R. S. Mehta, K. Rezvani, A. Olson et al., "Novel techniques for ex vivo expansion of cord blood: clinical trials," Frontiers in Medicine, vol. 2, article 89, 2015.

[100] Y. Wang, F. Chen, B. Gu, G. Chen, H. Chang, and D. Wu, "Mesenchymal stromal cells as an adjuvant treatment for severe late-onset hemorrhagic cystitis after allogeneic hematopoietic stem cell transplantation," Acta Haematologica, vol. 133, no. 1, pp. 72-77, 2015.

[101] B. Gokcinar-Yagci, O. Ozyuncu, and B. Celebi-Saltik, "Isolation, characterisation and comparative analysis of human umbilical cord vein perivascular cells and cord blood mesenchymal stem cells," Cell and Tissue Banking, vol. 17, no. 2, pp. 345-352, 2015.

[102] J. Liang, F. Wang, D. Wang et al., "Transplantation of mesenchymal stem cells in a laryngeal carcinoma patient with radiation myelitis," Stem Cell Research and Therapy, vol. 6, article 213, 2015.

[103] J. Kumar, V. Kale, and L. Limaye, "Umbilical cord blood-derived $\mathrm{CD}_{11 \mathrm{c}^{+}}$dendritic cells could serve as an alternative allogeneic source of dendritic cells for cancer immunotherapy," Stem Cell Research \& Therapy, vol. 6, article 184, 2015.

[104] C. Zhang, Y. Zhu, Y. Zhang, L. Gao, N. Zhang, and H. Feng, "Therapeutic potential of umbilical cord mesenchymal stem cells for inhibiting myofibroblastic differentiation of irradiated human lung fibroblasts," The Tohoku Journal of Experimental Medicine, vol. 236, no. 3, pp. 209-217, 2015.

[105] L. Fu, Y. Liu, D. Zhang, J. Xie, H. Guan, and T. Shang, "Beneficial effect of human umbilical cord-derived mesenchymal stem cells on an endotoxin-induced rat model of preeclampsia," Experimental and Therapeutic Medicine, vol. 10, no. 5, pp. 18511856, 2015.

[106] S. Osone, T. Imamura, Y. Fukushima-Nakase et al., "Case reports of severe congenital neutropenia treated with unrelated cord blood transplantation with reduced-intensity conditioning," Journal of Pediatric Hematology/Oncology, vol. 38, no. 1, pp. 49-52, 2016.

[107] M.-Y. Chang, T.-T. Huang, C.-H. Chen, B. Cheng, S.-M. Hwang, and P. C. H. Hsieh, "Injection of human cord blood cells with hyaluronan improves postinfarction cardiac repair in pigs," Stem Cells Translational Medicine, vol. 5, no. 1, pp. 56-66, 2016.

[108] G. S. Travlos, "Normal structure, function, and histology of the bone marrow," Toxicologic Pathology, vol. 34, no. 5, pp. 548-565, 2006.

[109] E. Gschweng, S. De Oliveira, and D. B. Kohn, "Hematopoietic stem cells for cancer immunotherapy," Immunological Reviews, vol. 257, no. 1, pp. 237-249, 2014.

[110] R. Singh Mahla, "HIV-1 Infection: the functional importance of SDF1, CCR2 and CCR5 in protection and therapeutics," Health Care: Current Reviews, vol. 3, article 150, 2015.

[111] T. Miyamoto and H. Nakauchi, "Generation of functional organs from pluripotent stem cells," The Japanese Journal of Clinical Hematology, vol. 56, pp. 2213-2219, 2015.

[112] R. Morizane, A. Q. Lam, B. S. Freedman, S. Kishi, M. T. Valerius, and J. V. Bonventre, "Nephron organoids derived from human pluripotent stem cells model kidney development and injury," Nature Biotechnology, vol. 33, no. 11, pp. 1193-1200, 2015.

[113] S. P. Lukashyk, V. M. Tsyrkunov, Y. I. Isaykina et al., "Mesenchymal bone marrow-derived stem cells transplantation in patients with HCV related liver cirrhosis," Journal of Clinical and Translational Hepatology, vol. 2, no. 4, pp. 217-221, 2014. 
[114] M. Takasato, P. X. Er, H. S. Chiu et al., "Kidney organoids from human iPS cells contain multiple lineages and model human nephrogenesis," Nature, vol. 526, no. 7574, pp. 564-568, 2015.

[115] H. Benchetrit, S. Herman, N. Van Wietmarschen et al., "Extensive nuclear reprogramming underlies lineage conversion into functional trophoblast stem-like cells," Cell Stem Cell, vol. 17, no. 5, pp. 543-556, 2015.

[116] J. Lu, X. Zhong, H. Liu et al., "Generation of serotonin neurons from human pluripotent stem cells," Nature Biotechnology, vol. 34, no. 1, pp. 89-94, 2016.

[117] K. Takahashi and S. Yamanaka, "Induced pluripotent stem cells in medicine and biology," Development, vol. 140, no. 12, pp. 2457-2461, 2013.

[118] V. L. Mascetti and R. A. Pedersen, "Human-mouse chimerism validates human stem cell pluripotency," Cell Stem Cell, vol. 18, no. 1, pp. 67-72, 2016.

[119] P. Comizzoli and W. V. Holt, "Recent advances and prospects in germplasm preservation of rare and endangered species," Advances in Experimental Medicine and Biology, vol. 753, pp. 331-356, 2014.

[120] I. Dobrinski and A. J. Travis, "Germ cell transplantation for the propagation of companion animals, non-domestic and endangered species," Reproduction, Fertility and Development, vol. 19, no. 6, pp. 732-739, 2007.

[121] I. F. Ben-Nun, S. C. Montague, M. L. Houck et al., "Induced pluripotent stem cells from highly endangered species," Nature Methods, vol. 8, no. 10, pp. 829-831, 2011.

[122] R. Verma, M. K. Holland, P. Temple-Smith, and P. J. Verma, "Inducing pluripotency in somatic cells from the snow leopard (Panthera uncia), an endangered felid," Theriogenology, vol. 77, no. 1, pp. 220-228.e2, 2012.

[123] L. Pothana, H. Makala, L. Devi, V. P. Varma, and S. Goel, “Germ cell differentiation in cryopreserved, immature, Indian spotted mouse deer (Moschiola indica) testes xenografted onto mice," Theriogenology, vol. 83, no. 4, pp. 625-633, 2015. 

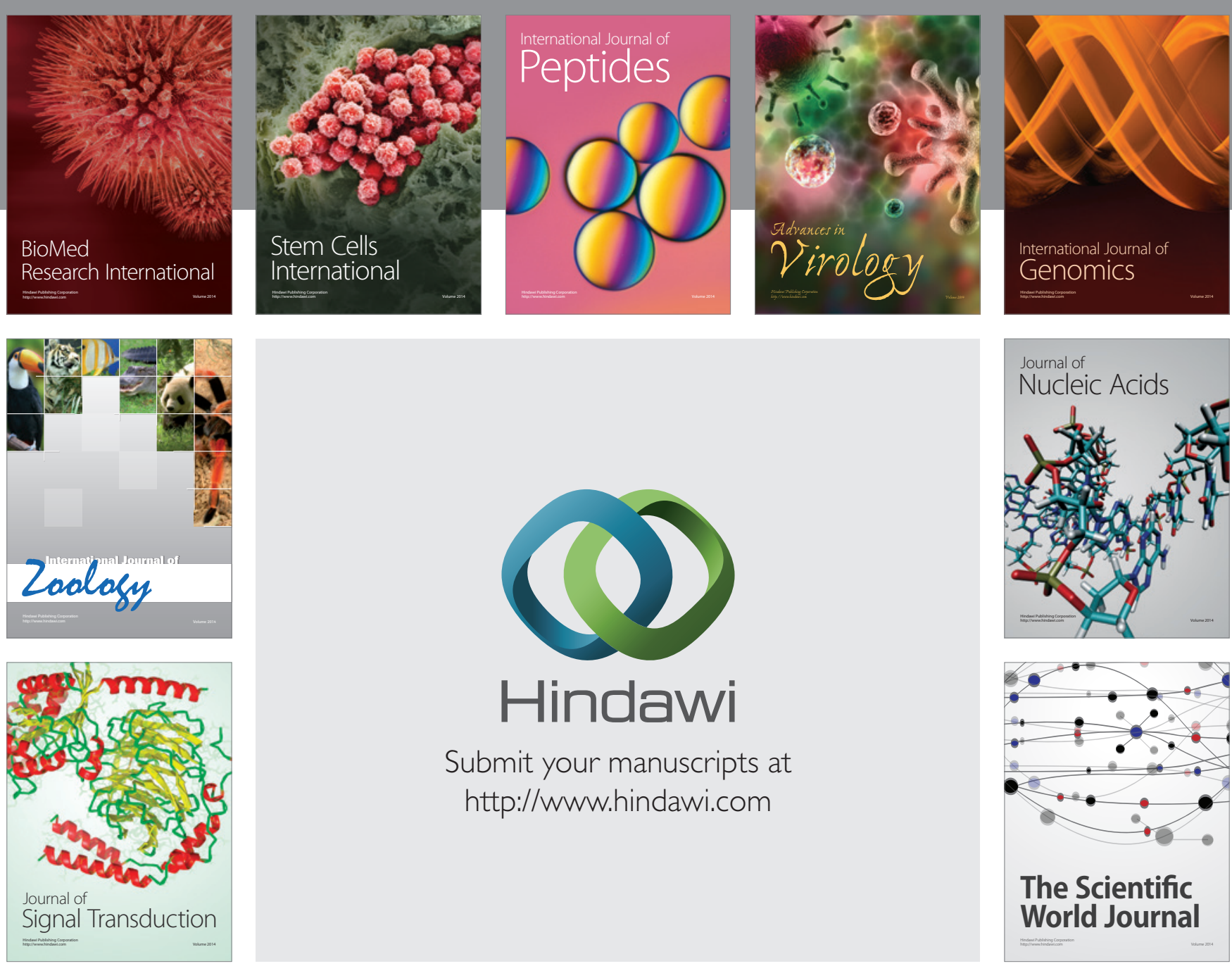

Submit your manuscripts at

http://www.hindawi.com
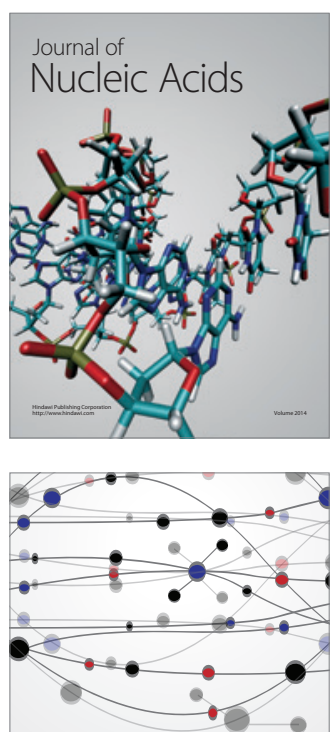

The Scientific World Journal
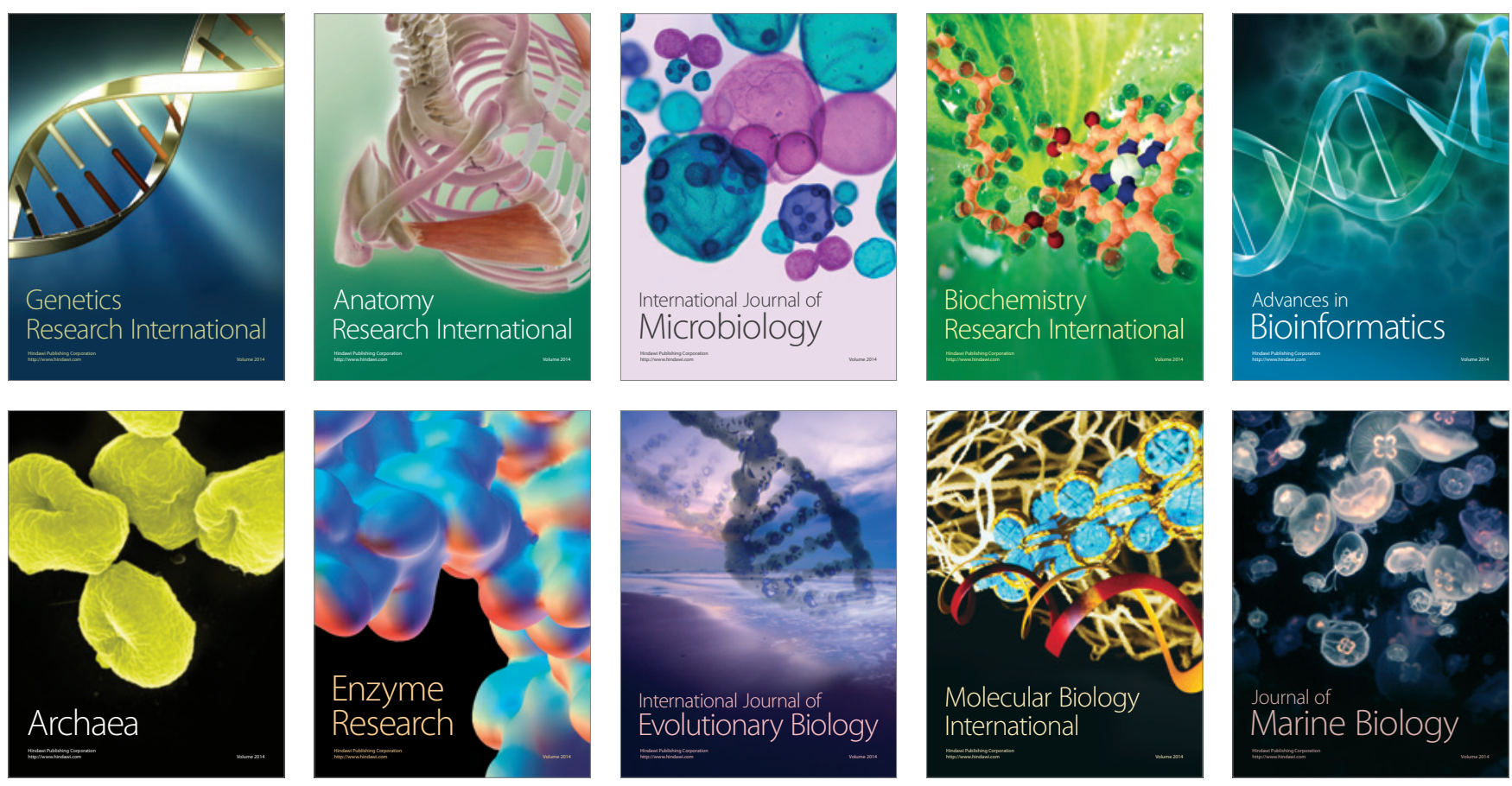